\title{
Downstream components of the calmodulin signaling pathway in the rice salt stress response revealed by transcriptome profiling and target identification
}

Worawat Yuenyong ${ }^{1}$, Aumnart Chinpongpanich', Luca Comai ${ }^{2}$, Supachitra Chadchawan ${ }^{3,4}$ and Teerapong Buaboocha ${ }^{1,3,4^{*}}$

\begin{abstract}
Background: Calmodulin (CaM) is an important calcium sensor protein that transduces $\mathrm{Ca}^{2+}$ signals in plant stress signaling pathways. A previous study has revealed that transgenic rice over-expressing the calmodulin gene OsCam 1-1 (LOC_Os03g20370) is more tolerant to salt stress than wild type. To elucidate the role of OsCam 1-1 in the salt stress response mechanism, downstream components of the OsCam1-1-mediated response were identified and investigated by transcriptome profiling and target identification.

Results: Transcriptome profiling of transgenic 'Khao Dawk Mali 105' rice over-expressing OsCam 1-1 and wild type rice showed that overexpression of OsCam1-1 widely affected the expression of genes involved in several cellular processes under salt stress, including signaling, hormone-mediated regulation, transcription, lipid metabolism, carbohydrate metabolism, secondary metabolism, photosynthesis, glycolysis, tricarboxylic acid (TCA) cycle and glyoxylate cycle. Under salt stress, the photosynthesis rate in the transgenic rice was slightly lower than in wild type, while sucrose and starch contents were higher, suggesting that energy and carbon metabolism were affected by OsCam1-1 overexpression. Additionally, four known and six novel CaM-interacting proteins were identified by cDNA expression library screening with the recombinant OsCaM1. GO terms enriched in their associated proteins that matched those of the differentially expressed genes affected by OsCam 1-1 overexpression revealed various downstream cellular processes that could potentially be regulated by OsCaM1 through their actions.

Conclusions: The diverse cellular processes affected by OsCam1-1 overexpression and possessed by the identified CaM1-interacting proteins corroborate the notion that CaM signal transduction pathways compose a complex network of downstream components involved in several cellular processes. These findings suggest that under salt stress, CaM activity elevates metabolic enzymes involved in central energy pathways, which promote or at least maintain the production of energy under the limitation of photosynthesis.
\end{abstract}

Keywords: Calmodulin, CaM, Rice, Salt stress, Transcriptome

\footnotetext{
* Correspondence: Teerapong.B@chula.ac.th

'Department of Biochemistry, Faculty of Science, Chulalongkorn University,

Bangkok, Thailand

${ }^{3}$ Center of Excellent in Environment and Plant Physiology, Department of

Botany, Faculty of Science, Chulalongkorn University, Bangkok, Thailand

Full list of author information is available at the end of the article
}

(c) The Author(s). 2018 Open Access This article is distributed under the terms of the Creative Commons Attribution 4.0 International License (http://creativecommons.org/licenses/by/4.0/), which permits unrestricted use, distribution, and reproduction in any medium, provided you give appropriate credit to the original author(s) and the source, provide a link to the Creative Commons license, and indicate if changes were made. The Creative Commons Public Domain Dedication waiver (http://creativecommons.org/publicdomain/zero/1.0/) applies to the data made available in this article, unless otherwise stated. 


\section{Background}

Salinity stress is a major abiotic stress that affects plant growth, resulting in a loss of crop yield, especially rice, which is one of the most salt-sensitive plants in comparison to other cereals [1]. Salt stress affects plants via both osmotic and ionic effects. Osmotic effects result in a reduction of water absorption ability such that the effects are similar to drought stress. Ionic stress causes $\mathrm{Na}^{+}$toxicity, which disrupts photosynthesis, protein synthesis, and enzyme activity [2, 3]. Numerous reports have shown negative effects of salt stress on rice growth and productivity based on the total chlorophyll content, protein concentration [4], photosynthetic $\mathrm{CO}_{2}$ fixation, stomatal conductance, transpiration [5], shoot dry weight, tiller number per plant, spikelets per panicle, and grain yield [6].

$\mathrm{Ca}^{2+}$ is a crucial second messenger consisting of a transient elevation of cytosolic $\left[\mathrm{Ca}^{2+}\right]$. The $\mathrm{Ca}^{2+}$ signals are transduced and decoded via $\mathrm{Ca}^{2+}$ binding protein, and then the information is relayed to downstream responses. The signals are mainly transduced through kinases mediating the phosphorylation cascade, resulting in downstream response regulation, including changes in gene expression through the regulation of transcription factors [7]. Calcium signaling is used to respond to environmental stimuli, as well as to coordinate growth and development in plants. In the plant calcium signal transduction process, calcium sensors, including calmodulin $(\mathrm{CaM})$, calcineurin B-like $(\mathrm{CBL})$ protein and $\mathrm{Ca}^{2+}$-dependent protein kinase (CPK), play important roles in the transduction of various stimuli $[8,9]$.

$\mathrm{CaM}$ is a protein that contains characteristic EF-hand motifs that bind $\mathrm{Ca}^{2+}$ ions with high affinity and specificity [10]. CaM binding to $\mathrm{Ca}^{2+}$ leads to the exposure of hydrophobic regions on the molecule surface and subsequent interactions with target proteins or nucleic acids [11]. Rice carries 5 CaM-encoding genes: OsCam1-1, OsCam1-2, OsCam1-3, OsCam2 and OsCam3 [12]. The expression of OsCam1-1 increases to a great extent in response to $\mathrm{NaCl}$, mannitol and wounding treatment [13]. Several lines of evidence have revealed that calcium sensors are involved with an enhanced abiotic tolerance capacity in plants [14]. Evidence has shown that the constitutive expression of bovine calmodulin in tobacco results in a shortened germination time of transgenic tobacco seeds under salt stress (120-160 mM NaCl) [15]. Arabidopsis overexpressing GmCaM4 (Glycine max calmodulin) exhibit increased expression of AtMYB2-regulated genes, including proline-synthesizing enzymes, suggesting that this feature confers salt tolerance to the transgenic Arabidopsis by enabling the accumulation of proline [16]. Our previous report have shown that transgenic rice over-expressing OsCam1-1 grow better under salt stress than wild type [17]. Wu H. and colleagues have found that the biphasic $\mathrm{Ca}^{2+}$ signal and enhancement of OsCam1-1 expression in rice cause heat stress-mediated expression of downstream heat shock-related genes, and OsCam1-1 overexpression Arabidopsis are more tolerant to heat stress than its wild type [18]. In another report, AtCam3 knockout mutant Arabidopsis showed a clear reduction of thermotolerance after heat treatment at $45^{\circ} \mathrm{C}$, and when AtCam3 was overexpressed in mutant and wild type Arabidopsis, the thermotolerant ability was rescued and increased, respectively. Moreover, co-expression of some heat shock protein genes with AtCaM3 suggested that $A t C a m 3$ plays a key role in the $\mathrm{Ca}^{2+}$-CaM heat shock transduction pathway [19]. The versatile functions of CaM are interesting, especially the role in the regulation of gene expression. CaM proteins directly modulate transcription factors (TFs), and some of these TFs have been verified to play roles in stress signaling pathways; however, the $\mathrm{Ca}^{2+}$ and $\mathrm{Ca}^{2+} / \mathrm{CaM}$-regulating TF mechanisms remain incompletely understood and require further investigation [20, 21]. Transcriptomics analysis can lead to the discovery of genes or processes that respond to such factors. The aim of the present study was to investigate the downstream effects of OsCam1-1 overexpression on gene expression regulation in rice under salt stress using a transcriptomic approach and to identify the interacting proteins to elucidate the role of OsCam1-1 in the salt stress response mechanism.

\section{Results}

RNA-Seq of Rice overexpressing OsCam1-1 and differential gene expression analysis

$\mathrm{CaM}$ is a multifunctional protein that regulates the activities of numerous target proteins. Genome-wide analysis techniques such as transcriptome profiling are particularly suitable for identifying the downstream components that are potentially regulated by CaM. In our previous report [17], rice overexpressing OsCam11 showed a significantly higher relative growth rate than wild type when grown under salt stress. Here, transcriptome profiling of the 3-week-old rice leaves of transgenic rice over-expressing OsCam1-1 (L1) and its wild type (WT) under normal condition (NS) and salt stress $(150 \mathrm{mM} \mathrm{NaCl})$ conditions $(\mathrm{S})$ for $4 \mathrm{~h}$ was conducted. More than 185 million reads from eight libraries from single-end RNA-Seq by Illumina Hi-Seq 2000 were obtained, with a total read of each library between 22 and 25 million reads. The reads were processed by POPE [22], which provided a total clean read per library of more than $99 \%$ of the total reads. At least $93 \%$ of the clean reads were mapped to the rice genome reference, Michigan State University rice annotation project's MSU7 [23] and less than 11\% of the clean reads were multiple alignment reads (Table 1 ). 
Table 1 RNA-Seq read count information

\begin{tabular}{llllllll}
\hline Sample $^{a}$ & Raw Input Reads & Clean Reads & \% Clean Reads & Mapped Reads & \% Mapped Reads ${ }^{\mathrm{b}}$ & $\begin{array}{l}\text { Multiple } \\
\text { Alignment Reads }\end{array}$ & $\begin{array}{c}\text { \%Multiple } \\
\text { Alignment Reads }\end{array}$ \\
\hline WTNS R1 & $24,019,397$ & $23,961,896$ & 99.76 & $22,973,989$ & 95.88 & $1,952,214$ & 8.15 \\
WTNS R2 & $22,859,782$ & $22,779,097$ & 99.65 & $21,709,287$ & 95.30 & $2,029,217$ & 8.91 \\
WTS R1 & $23,050,208$ & $22,990,113$ & 99.74 & $21,979,140$ & 95.60 & $1,746,186$ & 7.60 \\
WTS R2 & $23,437,864$ & $23,362,805$ & 99.68 & $22,119,198$ & 94.68 & $2,102,270$ & 9.00 \\
L1NS R1 & $23,259,980$ & $23,234,303$ & 99.89 & $22,207,203$ & 95.58 & $2,048,681$ & 8.82 \\
L1NS R2 & $23,944,162$ & $23,859,454$ & 99.65 & $22,673,161$ & 95.03 & $2,110,311$ & 8.84 \\
L1S R1 & $22,358,313$ & $22,282,400$ & 99.66 & $21,248,337$ & 95.36 & $2,332,891$ & 10.47 \\
L1S R2 & $22,980,550$ & $22,928,854$ & 99.78 & $21,527,676$ & 93.89 & $1,739,326$ & 7.59
\end{tabular}

${ }^{a}$ R1 and R2 indicate biological replicates

${ }^{\mathrm{b}}$ The $\%$ mapped reads and \% multiple alignment reads were calculated using the clean reads as a denominator

To compare the transcriptome profiles of the rice, differential gene expression analysis of the transcriptome data using DESeq [24] was carried out, which provided the number of differentially expressed genes (DEGs) summarized in Table 2. Analysis of the wild type identified 12,184 DEGs $(p<0.05)$ between the transcriptome profile under normal and salt stress conditions (WTNSWTS), in which 5842 and 6342 genes were up-regulated and down-regulated, respectively. For transgenic rice over-expressing OsCam1-1, comparisons between normal and salt stress conditions (L1NSL1S) revealed a total of 13,259 DEGs with 6434 and 6825 up-regulated and down-regulated genes, respectively. Furthermore, the transcriptome profiles of the transgenic rice were compared with those of the wild type. Under normal conditions (WTNSL1NS), 2022 DEGs were identified, with 892 and 1130 DEGs expressed at higher or lower levels in the transgenic rice, respectively. Under salt stress, comparisons of transgenic rice with wild type rice (WTSL1S) revealed 1677 DEGs, with 957 and 720 DEGs expressed at higher or lower levels in the transgenic rice, respectively. The scatterplots showed quantitative overview of the four transcriptome profile comparisons (Fig. 1). OsCam1-1 was found to be highly expressed in transgenic rice under both normal and stress condition, with an average RPKM of 1758.67 and 1644.62, while the average RPKM of wild type under normal and stress conditions was 91.94 and 97.84 , respectively. The expression of OsCam1-1 in the wild type was not induced at $4 \mathrm{~h}$ after salt stress $(150 \mathrm{mM})$, in good agreement with a previous study. According to a gene expression study conducted by Chinpongpanich et al. [25], the transcript level of OsCam1-1 determined by qRT-PCR was highly induced at $1 \mathrm{~h}$ after $150 \mathrm{mM} \mathrm{NaCl}$ treatment and then sharply decreased after $1 \mathrm{~h}$. This result validated the overexpression of OsCam1-1 in transgenic rice with an approximately 18 -fold change in RPKM compared with wild type. Based on a differential transcriptome analysis, the gene expression levels of those 2022 and 1677 DEGs were thus likely affected by OsCam1-1 overexpression.

\section{qRT-PCR verification of the transcriptome data}

To verify the reliability of the transcriptome data, nine salt-responsive genes, $\beta$-amylase (LOC_Os03g22790), isocitrate lyase (LOC_Os07g34520), malate synthase (LOC_Os04g40990), aconitase (LOC_Os08g09200), glycosyl hydrolase (LOC_Os04g45290), ERD1 (LOC_Os02g 32520), AP2 (LOC_Os03g08470), isocitrate dehydrogenase (LOC_Os05g49760) and pyruvate decarboxylase (LOC_Os03g18220), were selected for qRT-PCR. Figure 2 shows the qRT-PCR results for seven genes, which agreed well with the transcriptome data. Compared with wild type, they all exhibited higher levels in transgenic rice, demonstrating a statistically significant difference under salt stress. In contrast, the expression of the other two genes examined by qRT-PCR did not

Table 2 Differential gene expression analysis results showing the number of significantly differentially expressed genes comparing each rice line and/or condition

\begin{tabular}{llll}
\hline $\begin{array}{l}\text { Comparison of rice line } \\
\text { and/or condition }\end{array}$ & $\begin{array}{l}\text { Total number of differentially } \\
\text { expressed genes }(p<0.05)\end{array}$ & $\begin{array}{l}\text { Number of differentially } \\
\text { up-regulated genes }(p<0.05)\end{array}$ & $\begin{array}{l}\text { Number of differentially } \\
\text { down-regulated genes }(p<0.05)\end{array}$ \\
\hline WTNSWTS & 12,184 & 5842 & 6342 \\
L1NSL1S & 13,259 & 6434 & 6825 \\
WTNSL1NS & 2022 & 892 & 1130 \\
WTSL1S & 1677 & 957 & 720 \\
\hline
\end{tabular}



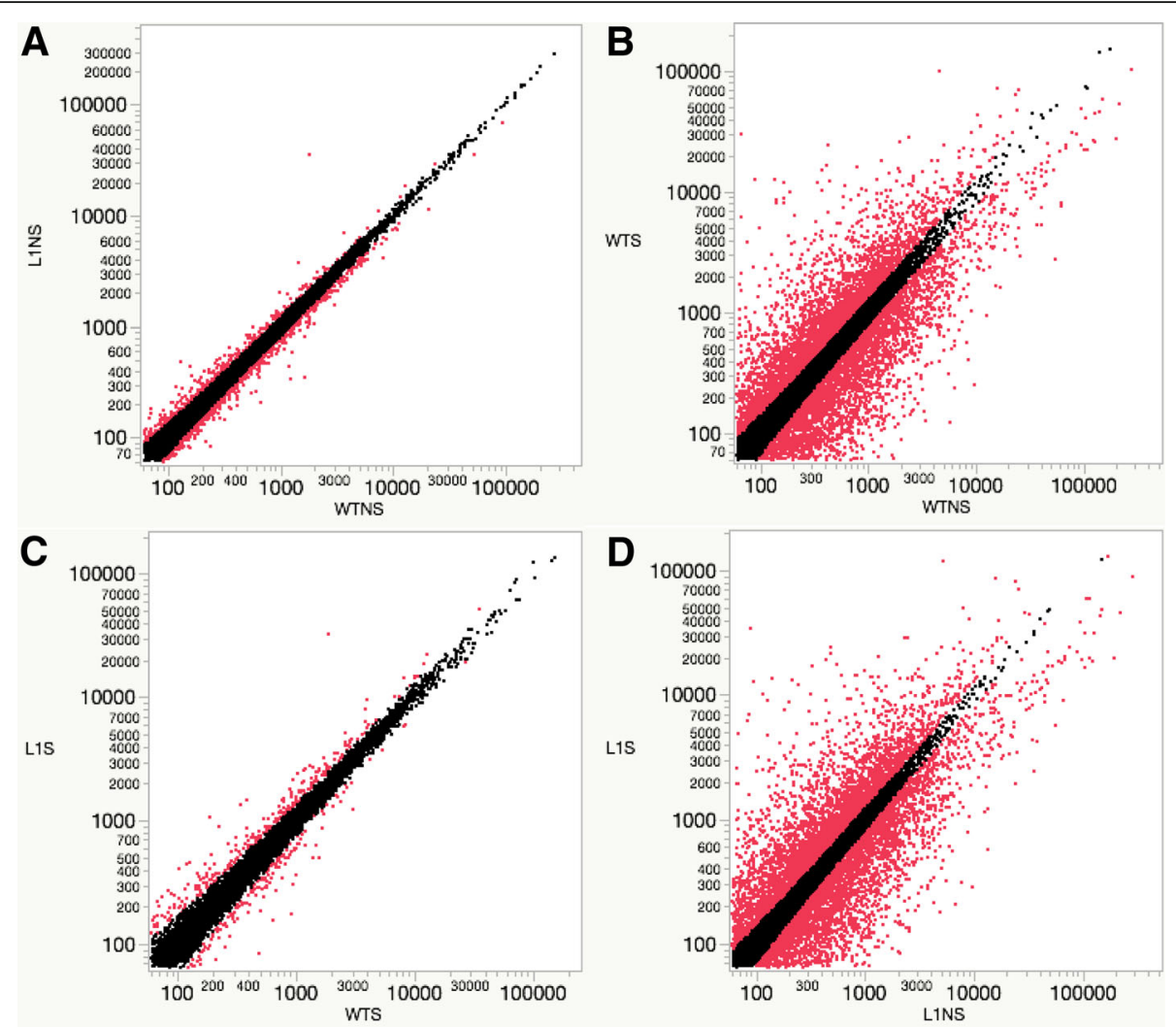

Fig. 1 Scatter plot showing significantly differential gene expression $(p<.05)$ comparing different rice lines and/or conditions. a Comparison of wild type under normal condition (WTNS) and 35S-OsCam1-1 under normal conditions (L1NS), b wild type under normal conditions (WTNS) and wild type under stress conditions (WTS). $\mathbf{c}$ wild type under stress conditions (WTS) and 35S-OsCam1-1 under stress conditions (L1S). d 35SOsCam1-1 under normal conditions (L1NS) and 35S-OsCam1-1 under stress conditions (L1S). The X and $\mathrm{Y}$ axes represent the base mean for the RNA-seq data

agree well with the transcriptome data (data not shown), potentially because of their low expression levels.

\section{Gene ontology enrichment analysis}

To categorize the DEGs, Venn diagrams were constructed from the four comparisons. The first Venn diagram was constructed from the salt-responsive DEGs from either wild type (WTNSWTS, blue colored circle) or transgenic rice (L1NSL1S, red colored circle) and the DEGs that were expressed at higher levels in the transgenic rice either under normal (WTNSL1NS_up, green colored circle) or salt stress (WTSL1S_up, yellow colored circle) conditions (Fig. 3a). In contrast, the second diagram was constructed from the salt-responsive DEGs and the DEGs that were expressed at lower levels in transgenic rice either under normal (WTNSL1NS_down, green colored circle) or salt stress (WTSL1S_down, yellow colored circle) conditions (Fig. 3b). According to the Venn diagrams, we identified 1328 salt-responsive DEGs with higher expression levels in transgenic rice, which will be referred to as HT salt-responsive DEGs (Fig. 3a, red line circle), and 1431 salt-responsive DEGs with lower expression levels in transgenic rice, which will be referred to as LT salt-responsive DEGs (Fig. 3b, red line circle). For those with unaffected expression levels by salt stress, 290 genes or 200 genes showed higher (Fig. 3a, blue line circle) or lower (Fig. 3b, blue line circle) expression levels in transgenic rice, which will be referred to as HT DEGs or LT DEGs, respectively. In both Venn diagrams, the largest of number DEGs with expression levels that did not differ between transgenic rice and wild type (green circles) were salt-responsive DEGs.

Gene enrichment analysis was performed using those 1328 HT salt-responsive DEGs. The results showed that, in terms of biological process, the terms of response to endogenous stimulus (GO:0009719), response to abiotic stimulus (GO:0009628), response to biotic stimulus (GO:0009607), response to stress (GO:0006950) and metabolic process (GO:0008152), were enriched, while for the term of molecular function, the terms of oxygen binding (GO:0019825), transcription factor activity (GO:0003700) and catalytic activity (GO:0003824) were overrepresented (Fig. 4a). For those 1431 LT salt-responsive DEGs, in terms of biological process, the terms of 


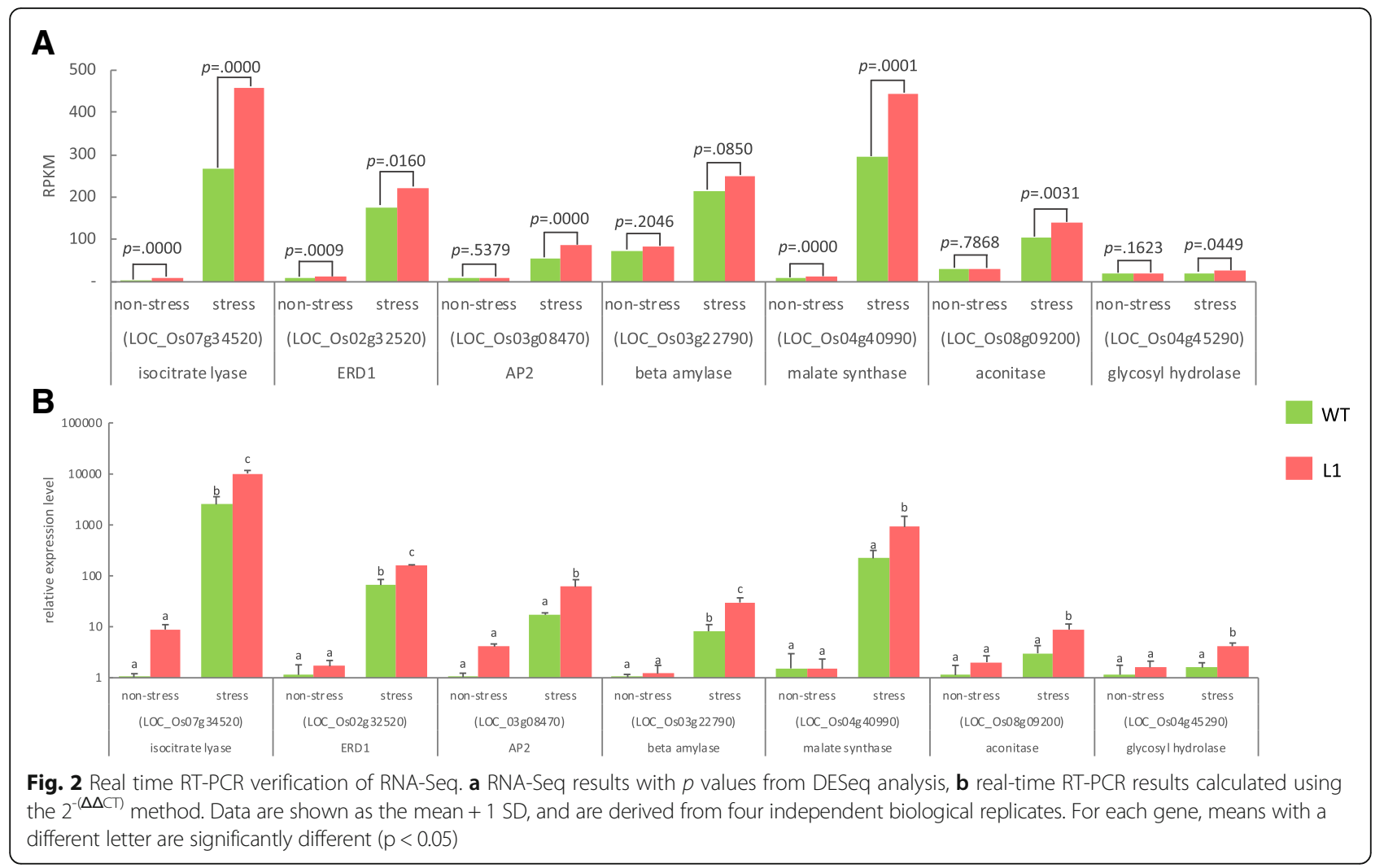

response to abiotic stimulus (GO:0009628), lipid metabolic process (GO:0006629), secondary metabolic process (GO:0019748), translation (GO:0006412), and photosynthesis (GO:0015979) were enriched, while in terms of the cellular compartment, the enriched terms included the thylakoid (GO:0009579), plastid (GO:0009536), cell wall (GO:0005618), intracellular organelles (GO:0043229), membrane (GO:0016020) and ribosome (GO:0005840), and in terms of molecular function, those of structural molecule activity (GO:0005198) and catalytic activity (GO:0003824) were overrepresented (Fig. 4b). Based on these results, we observed that the set of genes involving photosynthetic process were uniquely allocated in the LT salt-responsive DEGs, while genes involving response to stimuli and metabolic process were distributed in both HT and LT salt-responsive DEGs.

\section{Functional identification of OsCam1-1 regulated DEGs}

Table 3 summarizes the number of OsCam1-1-regulated DEGs in each functional category according to $\mathrm{GO}$ terms. For the categories of HT and LT DEGs with
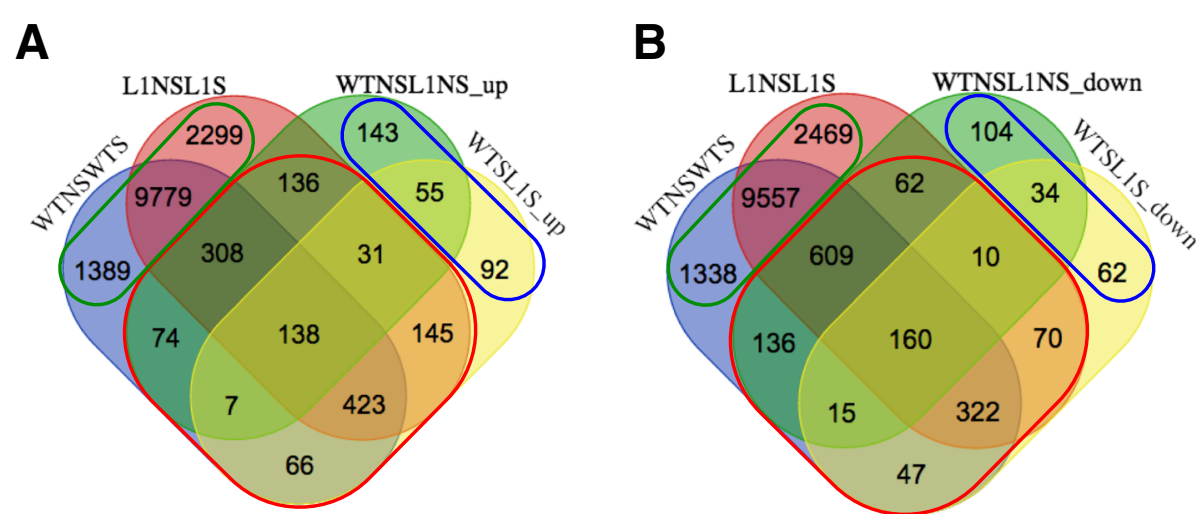

Fig. 3 Venn diagram showing (a) the number of significantly $(p<0.05)$ HT salt-responsive DEGs (red circle), HT DEGs (blue circle) and salt-responsive DEGs (green circle), while (b) shows the number of LT salt-responsive DEGs (red circle), LT DEGs (blue circle) and salt-responsive DEGs (green circle) 

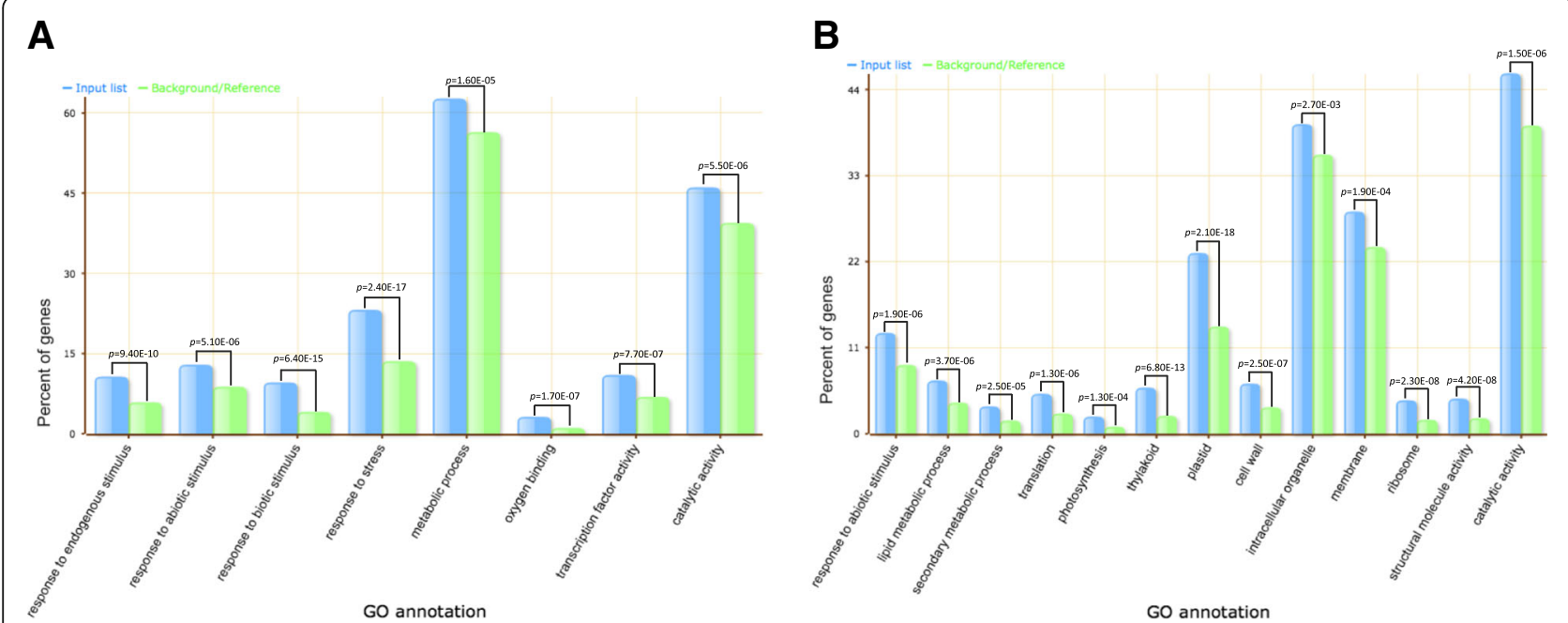

Fig. $4 \mathrm{GO}$ enrichment analysis results of (a) the salt-responsive DEGs with higher expression levels in transgenic rice and (b) the salt-responsive DEGs with lower expression levels in transgenic rice

expression levels that remained unchanged under salt stress, a small number of genes with diverse functions were found, which were involved in RNA regulation, protein metabolism, signaling, development, transport, hormone, and stress. However, the high-fold-changeDEGs were mainly identified as unknown proteins (see Additional file 1). Nonetheless, some known genes were annotated in the genome database including ankyrin repeat containing protein (LOC_Os01g09384), hexose carrier protein (LOC_Os11g38160), ATPase/hydrogen-translocating pyrophosphatase (LOC_Os01g23580), UDP glucosyltransferase (LOC_Os01g49240), C3HC4type RING finger (LOC_Os10g32760), cleavage and polyadenylation specificity factor $100 \mathrm{kDa}$ subunit (LOC_Os02g06940).

Overall, under salt stress, 1434 salt-responsive genes exhibited different expression levels between the wild type and transgenic rice. Figure 5 shows salt-responsive DEGs that encode potential downstream components of OsCaM1 in salt stress response. These DEGs are involved in several major cellular processes, including signaling and stress responses, hormone-mediate regulation, transcription, secondary metabolism, lipid metabolism, glycolysis, TCA cycle, glyoxylate cycle, photosynthesis, and carbohydrate metabolism. In signaling, the HT salt-responsive DEGs include LOC_Os06g49430, which encodes BWMK1, a rice MAP kinase; LOC_Os02g26720 and LOC_Os10g01480, which encode inositol 1,3,4-trisphosphate 5/6-kinase (IPTK); and LOC_Os04g54200, which encodes diacylglycerol kinase (DGK). Involved in stress response, the transcriptome results showed that the expression of 46 biotic and 19 abiotic stress DEGs was allocated in the HT salt-responsive DEG category (see Additional file 1).
These include a universal stress protein (USP) (LOC_Os07g36600), and a xylanase inhibitor protein gene (OsXIP2) (LOC_Os05g15770). For those involved in hormone-mediated regulation, we have identified three lipoxygenase (LOX) genes (LOC_Os08g39840, LOC_Os12g37350, and LOC_Os03g49380) and three 12-oxo-PDA-reductase $(O P R)$ genes (e.g. LOC_Os06g 11210, LOC_Os06g11290, and LOC_Os01g27230), which encode enzymes in the jasmonate (JA) biosynthesis pathway. In addition, the genes encoding key enzymes in the ABA biosynthesis pathway, 9-cis-epoxycarotenoid dioxygenase (NCED) (LOC_Os07g059

40) and abscisic aldehyde oxidase (AAO) (LOC_Os07g1 8120), were identified as HT salt-responsive DEGs, which were up-regulated approximately 1.9 -fold and 1.6-fold, respectively in transgenic rice compared with wild type rice under salt stress.

According to the transcriptome results, thirteen APETALA2/ethylene-responsive element binding protein (AP2/EREBP) genes were identified as HT salt-responsive DEGs (e.g. LOC_Os09g35030, LOC_Os09g35

010), while five AP2/EREBP genes were identified as LT salt-responsive DEGs (see Additional file 1). In addition, eight MYB genes were found allocated in the category of HT salt-responsive DEGs (e.g. LOC_Os01g74410) and 16 HT salt-responsive DEGs were WRKY, which is a large TF family that responds to plant stress (e.g. LOC_Os05g27730, LOC_Os02g084 40, LOC_Os01g54600, LOC_Os09g25070). In secondary metabolism, 35 DEGs were identified as HT salt-responsive genes (see Additional file 1) such as a hydroxyphenylpyruvate dioxygenase (HPPD) gene (LOC_Os02g07160) and five laccase genes (e.g. LOC_Os12g15680, LOC_Os01g63180, LOC_Os01g63190). 
Table 3 Number of OsCam1-1-regulated DEGs in each functional category according to GO terms

\begin{tabular}{|c|c|c|c|c|c|}
\hline \multirow[t]{2}{*}{ GO Term } & \multicolumn{5}{|l|}{ Number of } \\
\hline & HT salt-responsive DEG & LT salt-responsive DEG & HT DEG & LT DEG & salt responsive DEG \\
\hline photosynthesis & 2 & 31 & 0 & 1 & 111 \\
\hline cell wall & 26 & 52 & 0 & 2 & 178 \\
\hline lipid metabolism & 30 & 55 & 1 & 3 & 233 \\
\hline $\mathrm{N}$ metabolism & 4 & 2 & 0 & 0 & 15 \\
\hline amino acid metabolism & 17 & 21 & 2 & 4 & 155 \\
\hline$S$ assimilation & 2 & 1 & 0 & 0 & 3 \\
\hline metal handling & 5 & 6 & 2 & 1 & 31 \\
\hline secondary metabolism & 35 & 50 & 9 & 3 & 185 \\
\hline hormone & 51 & 27 & 13 & 6 & 227 \\
\hline co-factor and vitamin metabolism & 2 & 5 & 0 & 1 & 35 \\
\hline tetrapyrrole synthesis & 0 & 13 & 1 & 0 & 19 \\
\hline major $\mathrm{CHO}$ metabolism & 7 & 7 & 2 & 0 & 61 \\
\hline stress & 66 & 54 & 14 & 7 & 420 \\
\hline redox & 6 & 16 & 1 & 2 & 116 \\
\hline polyamine metabolism & 2 & 0 & 0 & 0 & 8 \\
\hline nucleotide metabolism & 8 & 9 & 0 & 0 & 82 \\
\hline biodegradation of xenobiotics & 2 & 1 & 0 & 0 & 44 \\
\hline C1-metabolism & 0 & 3 & 0 & 1 & 14 \\
\hline miscellaneous & 138 & 145 & 22 & 15 & 750 \\
\hline RNA regulation & 126 & 113 & 26 & 15 & 1318 \\
\hline DNA synthesis & 9 & 25 & 2 & 8 & 224 \\
\hline protein metabolism & 130 & 164 & 28 & 17 & 1575 \\
\hline minor $\mathrm{CHO}$ metabolism & 11 & 6 & 1 & 2 & 65 \\
\hline signaling & 71 & 53 & 18 & 10 & 656 \\
\hline cell division & 13 & 48 & 8 & 5 & 329 \\
\hline development & 53 & 36 & 10 & 6 & 330 \\
\hline transport & 68 & 67 & 11 & 6 & 576 \\
\hline not assigned & 430 & 410 & 118 & 85 & 4151 \\
\hline glycolysis & 2 & 0 & 0 & 0 & 29 \\
\hline fermentation & 2 & 5 & 0 & 0 & 11 \\
\hline gluconeogenesis & 3 & 1 & 0 & 0 & 7 \\
\hline OPP & 2 & 1 & 0 & 0 & 15 \\
\hline TCA & 2 & 3 & 0 & 0 & 52 \\
\hline electron transport chain & 3 & 1 & 1 & 0 & 50 \\
\hline micro RNA & 0 & 0 & 0 & 0 & 1 \\
\hline Total & 1328 & 1431 & 290 & 200 & 12,076 \\
\hline
\end{tabular}

Functions of several HT salt-responsive DEGs involve in the energy metabolism. These included 30 DEGs in lipid metabolism (see Additional file 1) with examples including three 3-ketoacyl-CoA synthase genes (LOC_Os02g11070, LOC_Os05g49900 and LOC_Os02g56860), four class III lipase genes (LOC_Os01g15000, LOC_Os11g43760, LOC_Os02g43700 and LOC_Os05g49840), and four genes encoding enzymes involving beta oxidation (LOC_Os09g39410, LOC_Os03g07140, LOC_Os08g44360 and LOC_Os05g07090). Several HT salt-responsive DEGs are also involved in carbohydrate metabolism including a fructose bisphosphate aldolase (FBP) gene (LOC_Os09g02 540) and a phosphofructokinase (PFK) gene (LOC_Os05g 10650) in the glycolysis pathway; and an aconitase gene 

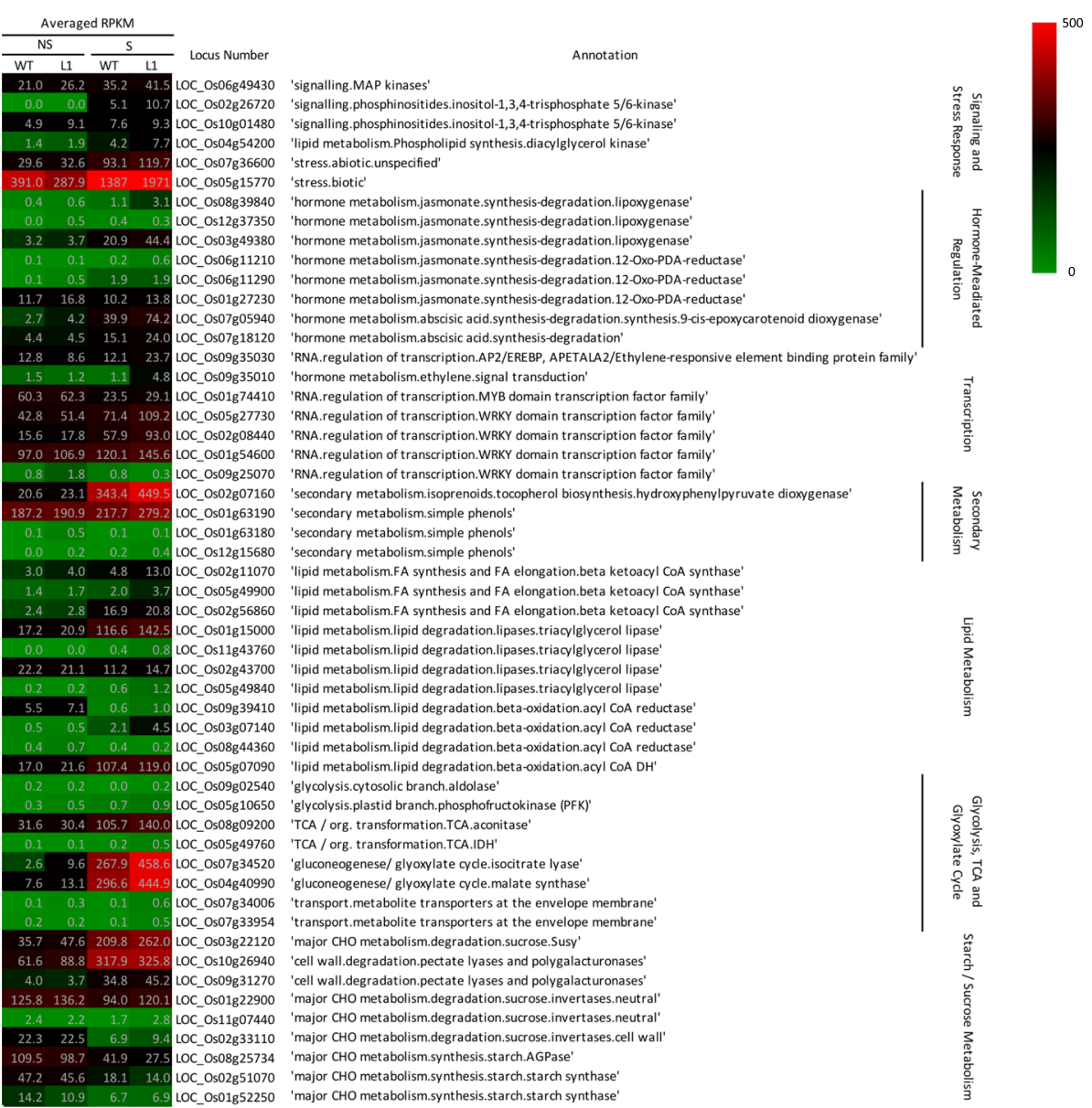

Fig. 5 Salt-responsive DEGs that encode potential downstream components of OsCaM1 in salt stress response. Expression levels of each gene by RPKM from wild type and transgenic rice under normal and salt stress conditions were presented as heat map

(LOC_Os08g09200) and an isocitrate dehydrogenase (IDH) gene (LOC_Os05g49760) in the TCA cycle. In addition, two genes encoding key enzymes in the glyoxylate cycle shuttling the TCA cycle pathway, isocitrate lyase (ICL) (LOC_Os07g34520) and malate synthase (MLS) (LOC_Os04g40990) were up-regulated approximately 1.7 -fold and 1.5 -fold, respectively in transgenic rice compared with wild type rice under salt stress. Additionally, the DEGs included two glucose6-phosphate transporter genes, LOC_Os07g34006 and LOC_Os07g33954, both with higher expression levels in transgenic rice under salt stress.

Finally, seven DEGs involved in sucrose and starch metabolism were allocated in the category of HT salt-responsive DEGs. Among these DEGs, sucrose synthase (LOC_Os03g22120) was up-regulated in both wild type or transgenic rice under salt stress, with greater up-regulation in transgenic rice. The transcriptome data also revealed three invertase genes (LOC_Os01g22900, LOC_Os11g07440, LOC_Os02g33110) and seven cell wall degradation DEGs, which were expressed at higher levels in transgenic rice (see Additional file 1) including two DEGs encoding polygalacturonase (LOC_Os10g26940 and LOC_Os09g31270).

When these salt-responsive DEGs were mapped onto metabolic pathways, several genes with consistent changes in their expression levels within certain pathways were observed, including the light reactions and Calvin cycle of the photosynthetic process, sucrose and starch metabolism, and central energy pathways. In Fig. 6 and Fig. 7, gene expression ratios between the transgenic rice and the wild type rice both under normal and salt stress conditions are presented for each corresponding step of these pathways. Overall, expression levels of 31 out of 33 DEGs in the photosynthetic process (e.g., chlorophyll a/b binding protein, protein subunit in photosystem I and II, ferredoxin, plastoquinone dehydrogenase complex, ribulose-bisphosphate carboxylase, which were repressed by salt stress) were lower in the transgenic rice overexpressing OsCam1-1 (Fig. 6) (see Additional file 2). In Fig. 7, the expression levels of several genes involved in sucrose degradation 


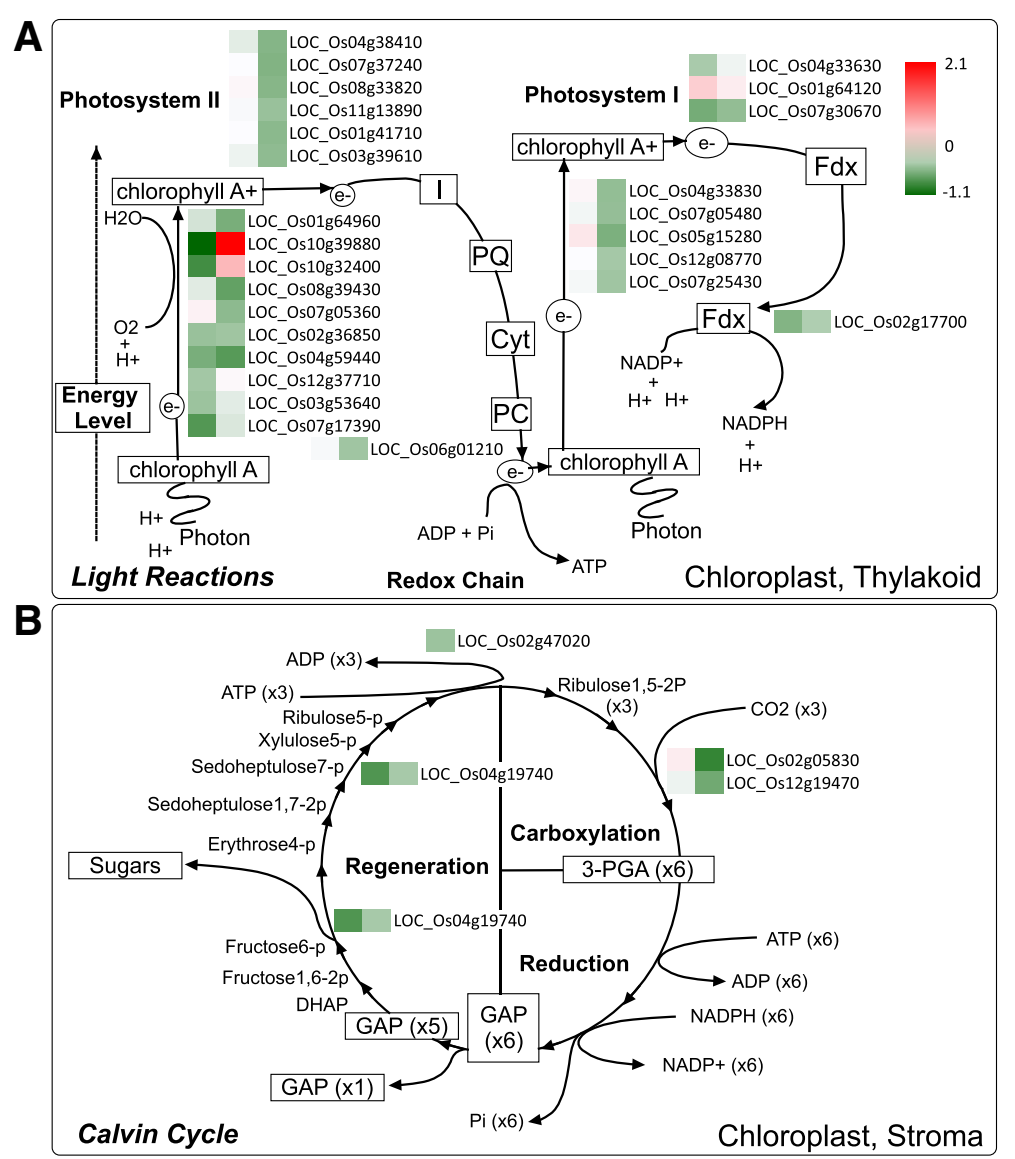

Fig. 6 Photosynthetic pathway showing the expression level and role(s) of the genes in the light reaction (a) and Calvin cycle. b The left box shows the log2-fold change in comparisons of WT and transgenic plants under normal conditions, and the right box represents the log2-fold change under salt stress conditions

(e.g., LOC_Os03g22120 encoding sucrose synthase, which was highly induced by salt stress; LOC_Os01g22900 and LOC_Os02g33110 encoding invertase, which were repressed by salt stress) were higher in transgenic rice, especially under salt stress, while those of genes in the starch biosynthetic pathway (e.g., LOC_Os08g25734 encoding glucose-1-phosphate adenylyltransferase; LOC_Os02g51070 and Os01g52250 encoding starch synthase, which were repressed by salt stress) were lower in transgenic rice. In addition, genes involved in glycolysis and the TCA cycle (e.g., LOC_Os05g10650 encoding phosphofructokinase; and LOC_Os05g49760 encoding isocitrate dehydrogenase, which were induced by salt stress) were expressed at higher levels in transgenic rice. Remarkably, three genes in the glyoxylate cycle: LOC_Os08g09200, LOC_Os07g 34520, and LOC_Os04g40990 encoding aconitase, isocitrate lyase, and malate synthase, respectively, which were all highly induced by salt stress, were expressed at higher levels in transgenic rice both under normal and salt stress conditions (Fig. 7).
Rice overexpressing OsCam1-1 exhibited higher sucrose and starch contents under salt stress

In our previous report [17], OsCam1-1-overexpressing lines showed a significantly higher relative growth rate than wild type when grown under salt stress. Based on the genes identified herein, among which several were involved in central energy pathways, sucrose and starch levels were determined in the three independent lines (L1, L2, L7) under normal and salt stress $(150 \mathrm{mM}$ $\mathrm{NaCl})$ conditions at day 3 and 5 after treatment. Salt stress led to a significant reduction of the starch level and slightly decreased sucrose levels in both wild type and transgenic rice lines. Noticeably, at day 3 , the transgenic lines could maintain the sucrose and starch levels better than the wild type under salt stress conditions. At day 5, the trends observed for sucrose and starch levels in transgenic rice under salt stress conditions were similar to those in wild type (Fig. 8).

In addition, the photosynthesis rate $\left(P_{\mathrm{n}}\right)$, stomatal conductance $\left(g_{\mathrm{s}}\right)$, intercellular carbon dioxide $\left(C_{\mathrm{i}}\right)$ and transpiration rate $(E)$ were examined in the transgenic 


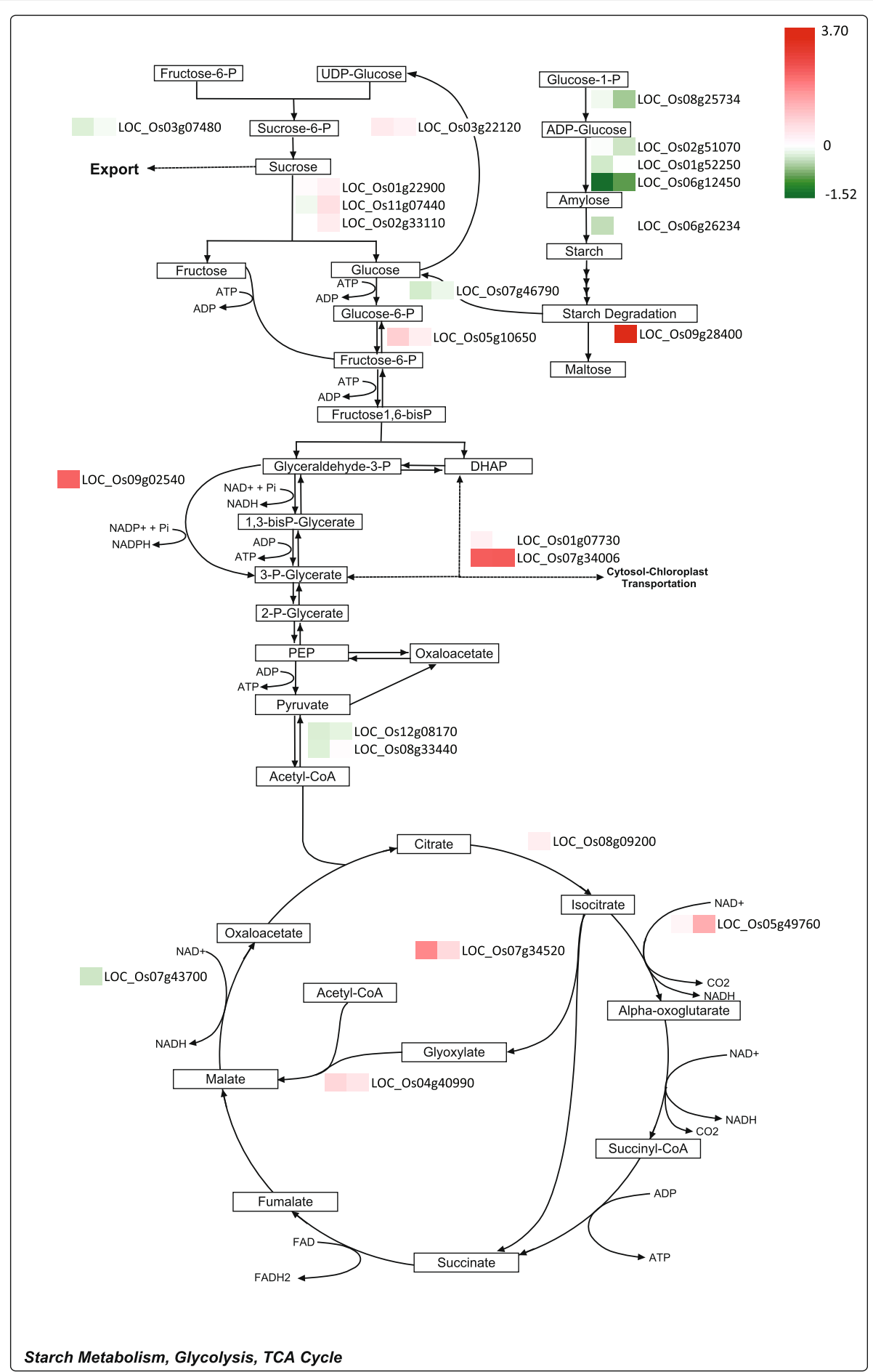

Fig. 7 Carbohydrate and energy metabolism pathway consisting of sucrose-starch metabolism, glycolysis and the TCA cycle show the gene expression level and function in metabolism. The left box shows the log2-fold change of comparisons of WT and the transgenic plants under normal conditions, and the right box represents the log2-fold change under salt stress conditions

rice over-expressing OsCam1-1. Under salt stress, $P_{\mathrm{n}}$, $g_{\mathrm{s}}$ and $E$ decreased at both day 3 and day 5 , while $C_{\mathrm{i}}$ decreased slightly at day 3 of treatment. Interestingly, transgenic rice had slightly lower $P_{\mathrm{n}}$ values than wild type rice at both day 3 and day 5 and tended to have lower $g_{\mathrm{s}}$ and $E$ values at day 5 of salt stress treatment. In contrast, the $C_{\mathrm{i}}$ measurements did not reveal significant difference between the transgenic and wild type 


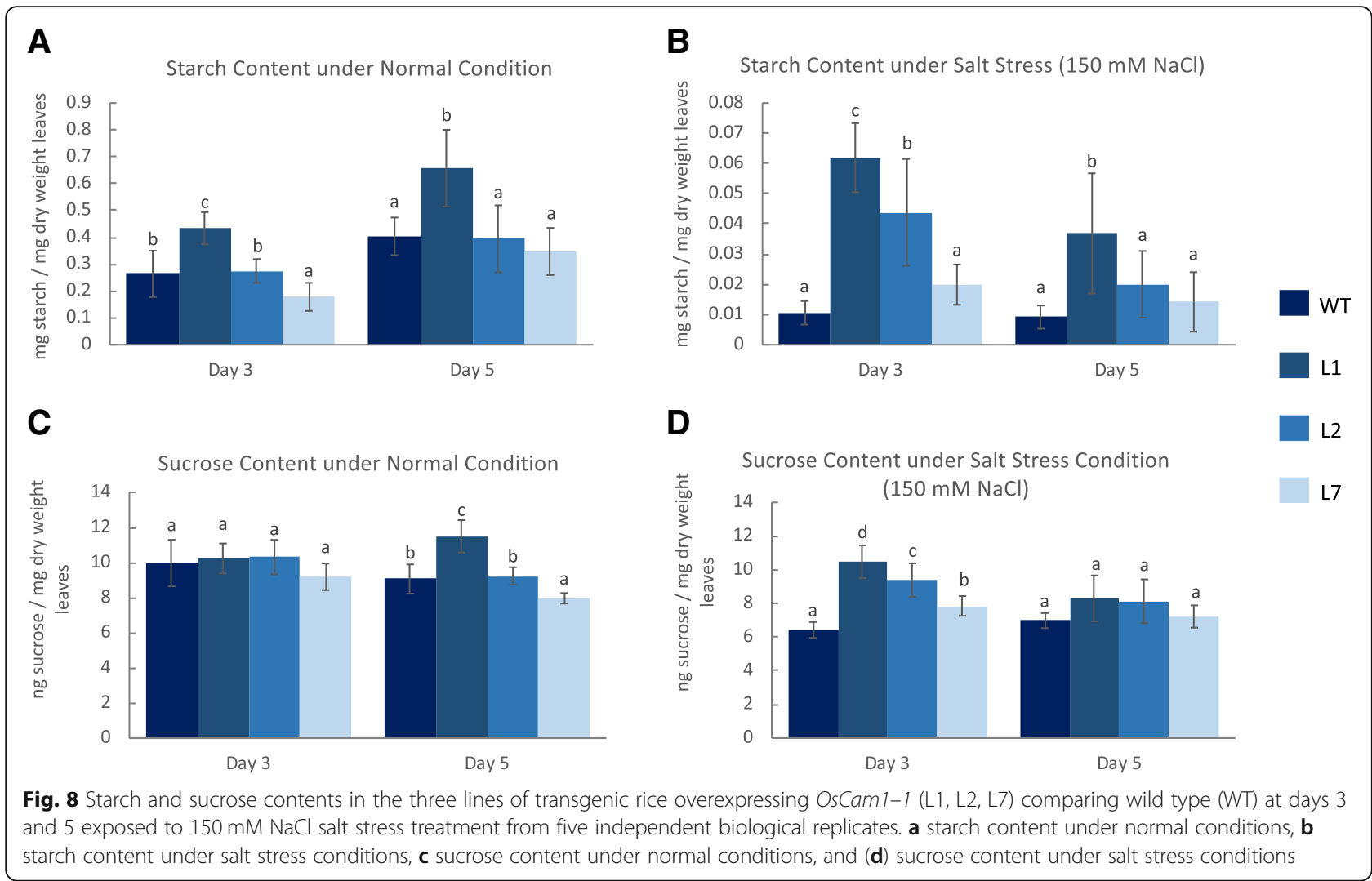

(Fig. 9). For FV'/FM', which reflects the maximum efficiency of photosystem II [26], no change was observed under the given salt stress conditions, and the transgenic rice did not exhibit difference either under normal or salt stress conditions compared with the wild type (see Additional file 3).

In a previous study, the northern blot results showed the highest expression levels of OsCam1-1 in transgenic rice line $\mathrm{L} 1$ among the three transgenic rice lines [17]. Under both normal and salt stress conditions, the sucrose and starch content correlated with the expression level of OsCam1-1 in those transgenic rice lines.

\section{Identification of OsCaM1-interacting proteins}

$\mathrm{CaM}$ does not possess functional domains other than EF hand motifs, so it functions by binding to and altering the activities of various interacting proteins. To understand how CaM1 mediates $\mathrm{Ca}^{2+}$-signal responses, its specific interacting proteins were identified using a cDNA expression library with ${ }^{35} \mathrm{~S}$-labeled rOsCaM1 protein as the probe. The purity of the prepared ${ }^{35} \mathrm{~S}$-labeled rOsCaM1 protein was examined by SDS-PAGE (see Additional file 4: Figure S3A). To test its specificity, PVDF membrane spotted with various amounts of CaMKII peptide [27], calcineurin [28], and BSA was incubated with the probe. The autoradiograph (see Additional file 4: Figure S3B) showed that the probe only interacted with CaMKII peptide and calcineurin but not BSA, and the intensity of the signal on the X-ray film was dose-dependent. The results indicated that the ${ }^{35} \mathrm{~S}$-labeled rOsCaM1 protein could specifically bind to well-known target proteins in the presence of $\mathrm{Ca}^{2+}$.

After screening the cDNA library, the purified clones from the tertiary screening were titered before performing single-clone excision. As a result, 10 distinct positive cDNA clones were obtained. All unique pBluescript SK(-) plasmids obtained from the single-clone excision were sequenced to determine the cloned cDNA insert sequences. The resulting sequences were BLASTsearched against the Rice Genome Annotation Project (MSU-RGAP) and the Rice Annotation Project (RAP) databases [29]. The functions of 8 OsCaM1 targets were identified (Table 4), which were diverse and potentially involved in various cellular processes, including metabolism, transcription, movement of organelles and vesicles, membrane transport, and signal transduction. Four known CaM-binding proteins previously identified in other plants were obtained from this screening, which included a cyclic nucleotide-gated ion channel [30] (LOC_Os06g33570), a glutamate decarboxylase [31] (LOC_Os03g51080), a CaM-binding transcription activator (CAMTA) [32] (LOC_Os04g31900), and a kinesin motor domain-containing protein [33] (LOC_Os04g571 40). The six identified putative novel CaM1-binding proteins 


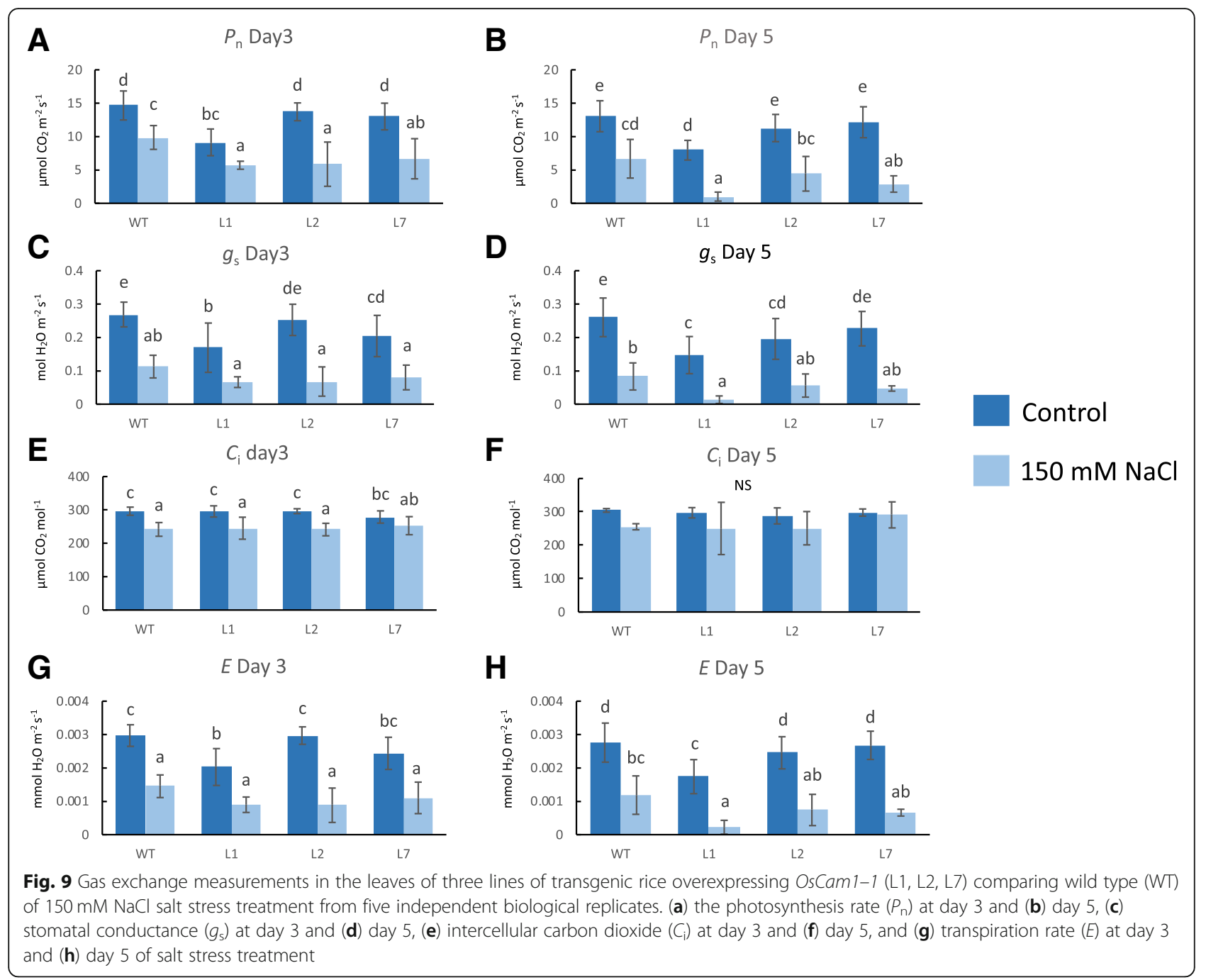

Table 4 OsCaM1 target gene list obtained by cDNA expression library screening

\begin{tabular}{|c|c|c|c|c|c|}
\hline Locus & Gene Annotation & Chromosome & ORF (bp) & $\begin{array}{l}\text { Protein } \\
\text { (aa residues) }\end{array}$ & $\begin{array}{l}\text { Protein Blot } \\
\text { Confirmation }\end{array}$ \\
\hline LOC_Os06g33570 & cyclic nucleotide-gated ion channel & 6 & 2085 & 694 & + \\
\hline LOC_Os03g51080 & glutamate decarboxylase & 3 & 1533 & 510 & + \\
\hline LOC_Os04g31900 & calmodulin-binding transcription activator & 4 & 3012 & 1003 & + \\
\hline LOC_Os04g57140 & kinesin motor domain containing protein & 4 & 3588 & 1195 & + \\
\hline LOC_Os02g39850 & hydroxyanthranilate hydroxycinnamoyltransferase & 2 & 1329 & 442 & + \\
\hline LOC_Os09g36220 & response regulator receiver domain-containing protein & 9 & 1872 & 623 & - \\
\hline LOC_Os05g38710 & lipin, N-terminal conserved region family protein & 5 & 2655 & 884 & + \\
\hline LOC_Os12g17310 & myosin heavy chain-containing protein & 12 & 1944 & 647 & + \\
\hline LOC_Os08g34060 & DUF1336 domain containing protein, expressed & 8 & 2292 & 763 & ${ }^{\mathrm{a}} \mathrm{ND}$ \\
\hline LOC_Os02g13060 & expressed protein & 2 & 699 & 232 & + \\
\hline
\end{tabular}


comprised a transferase family protein (LOC_Os02g39850), a response regulator receiver domain-containing protein (LOC_Os09g36220), a lipin (LOC_Os05g38710), a myosin heavy chain-containing protein (LOC_Os12g17310), and two proteins with unknown function, LOC_Os08g34060 and LOC_Os02g13060. Interaction of eight putative target proteins (Table 4) with OsCaM1 was confirmed by protein blot analysis (see Additional file 5).

\section{Statistical verification of OsCam1-1 affected DEGs and OsCaM1 targets}

Overall, by RNA Seq, 3249 genes were found to be differentially expressed between OsCam1-1-overexpressing rice and wild type. To confirm the validity of this gene list, a statistical approach was employed using Fisher's exact test to determine the statistical confidence of the data as being true. Of the 55,986 rice genes according to the MSU7 rice genome database (http://rice.plantbiology.msu.edu/analyses_facts.shtml) [23], 60 rice genes were co-expressed with OsCam1-1 by co-expression analysis using the web-based tool STRING (https://string-db.org/) [34], which were used as a reference list of known OsCam1-1-affected genes (see Additional file 6). Within this supposed known gene set, 30 genes were found in the list of 3249 OsCam1-1-affected genes based on the RNA-Seq results (see Additional file 7). By Fisher's exact test, genes in the known gene set were significantly over-presented in our list of 3249 OsCam1-1-affected genes with a calculated $p$-value of $1.52 \times 10^{-21}$.

Similarly, to confirm the validity of the ten putative OsCaM1 targets identified in this study, 60 rice homologs of known Arabidopsis CaM target proteins [35] were identified and used as a reference list of known OsCaM1 targets in rice (see Additional file 8). Within this supposed known protein set, 4 proteins were found in the present study list of 10 OsCaM targets identified by cDNA expression library screening. By Fisher's exact test, OsCaM1 targets in the known protein set were significantly over-represented in our list of 10 putative OsCaM1 target proteins with a calculated p-value of $2.49 \times 10^{-10}$.

\section{Discussion}

Based on the transcriptomics analysis, OsCam1-1 overexpression affects genes in several cellular processes, potentially contributing to rice salt tolerance. As the expression level of OsCam1-1 in transgenic rice was much higher than that in wild type, even under normal conditions, numerous DEGs exhibited altered expression levels in the transgenic rice (WTNSL1NS, green colored circles), suggesting that their functions likely confer advantages to plants in coping with future salt stress. Approximately $80 \%$ of these genes were salt-responsive, indicating a likely effect on the salt stress response of OsCam1-1 overexpression. Under salt stress, approximately $18.4 \%$ of the salt-responsive genes differentially expressed between the transgenic and wild type rice (Table 3), which are further discussed below in detail. However, it should be noted that DEGs with expression levels that remained unchanged under salt stress, categorized as HT DEGs and LT DEGs, might also contribute to the salt tolerance of transgenic rice. However, the high-fold-change-DEGs were mainly identified as unknown proteins (see Additional file 6). Nonetheless, some known genes, which were annotated in the genome database, were found to be involved in salt stress or at least in abiotic stress responses, including ankyrin repeat containing protein (LOC_Os01g09384), hexose carrier protein (LOC_Os11g38160), ATPase/hydrogen-translocating pyrophosphatase (LOC_Os01g23580), UDP glucosyltransferase (LOC_Os01g49240), C3HC4-type RING finger (LOC_Os10g32760), cleavage and polyadenylation specificity factor $100 \mathrm{kDa}$ subunit (LOC_Os02g06940).

\section{Signaling and stress responses}

The mitogen-activated protein kinase (MAPK/MPK) cascade is a highly conserved central regulator of diverse cellular processes [36]. CaM plays role in the MAPK/MPK cascade by binding to mitogen-activated protein kinase (MPK) and/or mitogen-activated protein kinase phosphatase (MKP) [37, 38]. A rice MAPK, BWMK1 encoded by an HT salt-responsive DEG, could phosphorylate the OsEREBP1 transcription factor for binding to the GCC box element (AGCCGCC), which is a basic component of several pathogenesis-related gene promoters [39]. Inositol 1,3,4-trisphosphate 5/6-kinase (IPTK) encoded by two HT salt-responsive DEGs, phosphorylates inositol 1,3,4-trisphosphate to form inositol 1,3,4,5-tetrakisphosphate and inositol 1,3,4,6, tetrakisphosphate, which are ultimately converted to inositol hexaphosphate (IP6) and play roles in plant growth and development [40]. In rice, the T-DNA mutant of an IPTK gene showed reduced osmolyte accumulation and growth under drought conditions, and some genes involved in osmotic adjustment and reactive oxygen species scavenging were down-regulated. In addition, overexpression of DSM3 (OsITPK2) resulted in a decrease in inositol trisphosphate (IP3), and the phenotypes were similar to the mutant under salt and drought stress conditions. These findings suggested that DSM3 might play a role in fine-tune balancing the inositol phosphate level when plants are exposed to stress or during development [41]. Diacylglycerol kinase (DGK) encoded by an HT salt-responsive DEG, catalyzes the conversion of diacylglycerol (DAG) to phosphatidic acid (PA) [42], and PA plays a role in the stress signaling pathway, including the MAPK/MPK cascade [43]. A report has shown that the expression of OsBIDK1 encoding rice DGK is induced by benzothiadiazole and fungal infection. Moreover, 
transgenic tobacco constitutively expressing OsBIDK1 was more tolerant to plant pathogenic virus and fungi [44]. These findings suggest that several genes in the signaling process might be enhanced by OsCam1-1 under salt stress.

Interestingly, a universal stress protein (USP) gene was identified as an HT salt-responsive DEG. Evidence has shown that the expression of tomato USP ( $s p U S P$ ) is induced by drought, salt, oxidative stress and ABA, and overexpression of spUSP improves tomato drought tolerance via interactions with annexin, leading to the accumulation of ABA [45]. In addition, a xylanase inhibitor protein gene (OsXIP2), was highly expressed and induced by salt stress and OsCam1-1 overexpression. A previous report has shown that OsXIP can be induced by methyl jasmonate and wounding, so it was suggested that OsXIP may play a role in pathogen defense [46]. As many OsCam1-1 and/or salt stress affecting DEGs involve both biotic and abiotic stresses, OsCam1-1 may be a component that mediates the crosstalk of biotic stress and abiotic stress responses.

\section{Hormone-mediated regulation}

Plant hormones play a crucial role in acclimation to abiotic stress and regulate the growth and development and often alter gene expression [47, 48]. Our study revealed that the expression of several genes involved with hormones were changed due to the impact of OsCam1-1 overexpression under salt stress. Lipoxygenase $(L O X)$ encoded by three HT salt-responsive DEGs including homologs of AtLOX2 and AtLOX5, is the enzyme in the early step of the jasmonate (JA) biosynthesis pathway [49]. JA plays a role in the physiological response in plants under biotic and abiotic stress [50, 51]. An earlier report has shown that the absence of AtLOX2 expression results in no change under normal conditions, but JA accumulation induced by wounding is absent and the expression of $v s p$, a wound-JA-induced gene, is also suppressed [52]. In addition, three HT salt-responsive 12-oxo-PDA-reductase $(O P R)$ genes identified encode JA precursor-catalyzed enzyme that catalyzes the cis12-oxophytodienoic acid (OPDA) reduction reaction [53]. These findings suggest that the JA content might be enhanced by the overexpression of OsCam1-1 under salt stress by enhancing the production of enzymes in the JA biosynthesis pathway. In addition, the expression of $N C E D$ and $A A O$ genes participating in ABA biosynthesis [54] was altered by the influence of OsCam1-1 overexpression under salt stress. ABA biosynthesis is activated by abiotic stress through $\mathrm{Ca}^{2+}$ signaling and the phosphorylation cascade [55]. Our previous report has shown that the expression levels of NCED and AAO, and ABA content are enhanced in transgenic rice over-expressing OsCam1-1 under salt stress in comparison to wild type [17].

Collectively, the transcriptome indicates that OsCam11 overexpression likely has effects across biotic and abiotic stresses via plant hormonal regulation through JA and ABA. It has been suggested that biotic-abiotic stress crosstalk may occur via the MAPK/MPK cascade to regulate the plant hormone response to stress [56].

\section{Transcription}

Transcription factors (TFs) play roles as master regulators controlling clusters of genes [57] in the plant regulation of the stress response [58]. AP2/EREBP encoded by several HT salt-responsive DEGs, is in a large gene family of TFs that function in plant growth, primary and secondary metabolism, and response to hormones and environmental stimuli $[59,60]$. Two AP2/EREBP DEGs were identified as OsDREB1A and OsDREB1B [61], and a previous report has shown that OsDREB1A-overexpressing transgenic Arabidopsis exhibit induced expression of target stress-inducible genes of Arabidopsis DREB1A and increased tolerance to drought, high salt and freezing stress, as compared with wild type [62].

MYB, which was found encoded by several HT salt-responsive DEGs, is an important gene family of TFs, and several Arabidopsis MYB genes respond to hormone(s) or stress [63]. A previous report has shown that overexpression of OsMYB48-1, which is a member of those DEGs, resulted in enhanced salt and drought tolerance in rice. Furthermore, OsMYB48-1 also controlled ABA biosynthesis by regulating the expression of OsNCED4 and OsNCED5 in response to drought stress [64].

WRKY is a large TF family that responds to plant stress by regulating the plant hormone signal transduction pathway and is also involved in the biosynthesis of carbohydrate and secondary metabolites, senescence, and development [65]. According to several reports, WRKY genes identified here as HT salt-responsive DEGs are involved in the biotic stress response. The evidence shows that OsWRKY53 can bind to mitogen-activated protein kinases, OsMPK3 and OsMPK6, and inhibit their activity, resulting in a reduction of JA, jasmonoylisoleucine and ethylene production and causing a suppression of herbivore defense ability [66]. The expression of OsWRKY71 was induced by salicylic acid (SA), JA, and 1-aminocyclo-propane-1-carboxylic acid (ACC). Overexpression of OsWRKY71 affected the induction of OsNPR1 and OsPR1b expression, which are defense signaling genes, resulting in an enhancement of bacterial plant pathogen resistance [67]. WRKY13 has been shown to regulate crosstalk between abiotic and biotic stress by suppressing the SNAC1 and WRKY45-1 
genes, which are involved in drought and bacterial infection, by binding to W-like-type cis-elements on their gene promoters [68]. OsWRKY62, which was down-regulated by effect of OsCam1-1 overexpression and salt stress, was found in two splicing forms, short and full-length forms. Overexpression of the full-length form of OsWRKY62 resulted in the suppression of blast fungus resistance. In contrast, the knockout Oswrky62 line showed an enhanced defense-related gene expression level and accumulation of phytoalexins [69].

Based on the transcriptome profiles, OsCam1-1 overexpression clearly affected the expression of transcription factors that are well-known to regulate both biotic and abiotic stress responses. Therefore, OsCam1-1 likely functions through the activity of these transcription factors in mediating biotic-abiotic crosstalk regulation via diverse mechanisms. According to our transcriptomics data analysis, plant hormones might mediate the regulation of these TFs, leading to the downstream acclimated phenotypes in response to diverse stresses.

\section{Secondary metabolism}

Secondary metabolites play important roles in acclimating the plant to the environment and stress conditions [70]. A hydroxyphenylpyruvate dioxygenase (HPPD), which participates in the first committed reaction in the vitamin $\mathrm{E}$ biosynthesis pathway [71], was highly expressed and enhanced by the effect of either OsCam1-1 overexpression or salt stress. Previous evidence has shown that the expression of $H P P D$ responded to oxidative stress in barley leaf because it was induced by senescence, methyl jasmonate, ethylene, hydrogen peroxide and herbicide; paraquat and 3-(3,4-dichlorophenyl)-1,1-dimethylurea [72]. Furthermore, a report on the expression of two rice laccase $(L A C)$ genes (LOC_Os01g63180 and LOC_Os12g15680), which were identified as HT salt-responsive DEG here, in yeast cells suggested that the laccases played roles in atrazine and isoproturon herbicide detoxification [73]. In Arabidopsis, atlac1 and atlac2 mutants exhibited deficient root elongation under polyethylene glycol (PEG) treatment, while the atlac 8 mutant showed early flowering and the atlac15 mutant showed abnormal seed color. In addition, the evidence revealed that the expression level of $A t L A C 2$ was enhanced by salt and PEG treatment [74].

\section{Lipid metabolism}

Previous evidence has shown that 3-ketoacyl-CoA synthase encoded by three HT salt-responsive DEGs, plays a role in wax biosynthesis. The $k c s 1-1$ mutant exhibited reduced wax content, a thin seedling stem and low moisture sensitivity [75]. Another report has shown that the expression of KCS2O and KCS2/DAISY, two other Arabidopsis 3-ketoacyl-CoA synthase genes, is induced by salt, $\mathrm{ABA}$ and drought conditions and that these genes play roles in cuticular wax and suberin biosynthesis in root [76]. In addition, previous evidence has shown that Arabidopsis genes encoding class III triacylglycerol lipase encoded by four HT salt-responsive DEGs, are involved in many processes. At4g16070, which is orthologous to one of HT salt-responsive DEGs, was predicted to be a gene involved in stress or the $\mathrm{Ca}^{2+}$ signaling pathway. At4g16820 and At4g18550, which are orthologous to other rice DEGs are involved in seed germination, senescence or the stress response. At1g02660, which is orthologous to another rice DEG, is involved in the plant defense response signaling pathway [77]. Finally, an early report showed that acyl-CoA dehydrogenase, which was identified encoded by another salt-responsive DEG, functions in mitochondrial $\beta$-oxidation in maze root tip under glucose starvation conditions [78]. Based on these results, the activity of OsCam1-1 might affect lipid metabolism and possibly be linked to energy metabolism during salt stress.

\section{Glycolysis, TCA and Glyoxylate cycle}

Glycolysis and TCA cycle are essential in the respiratory pathway to generate energy [79]. Earlier comparative proteomic reports comparing salt-sensitive and salt-tolerant rice strains showed that the expression of FBP, which was identified as an HT salt-responsive DEG, was induced by salt stress in a salt-sensitive rice cultivar [80] and in either salt-sensitive or salt-tolerant strains of barley [81], while the activity of PFK encoded by another HT salt-responsive DEG, was increased under $\mathrm{NaCl}$ treatment along with that of pyruvate kinase and phosphoenolpyruvate carboxylase, resulting in an increase in respiratory $\mathrm{O}_{2}$ uptake and drastic changes in the levels of glycolytic metabolites in Bruguiera sexangula cell cultures [82]. The aconitase gene, which encodes the enzyme that isomerizes citrate to isocitrate in the early step of the TCA cycle, and the isocitrate dehydrogenase (IDH) gene, which encodes the enzyme that catalyzes the oxidative decarboxylation of isocitrate in the TCA cycle were also found in the HT salt-responsive DEG category. Previous studies have shown that in addition to its other function as an RNA binding protein, aconitase mediates resistance to oxidative stress in plants [83] and overexpression of maize $I D H$ in Arabidopsis enhances salt tolerance in Arabidopsis [84].

In addition, early reports suggested that ICL and MLS, which were identified as HT salt-responsive DEGs here, play a role in converting lipids to sugar using an acetyl unit from $\beta$-oxidation to generate the substrate of gluconeogenesis, and this process is important during the post-germination stage in Arabidopsis [85, 86]. Additionally, the HT salt-responsive DEGs included two glucose-6-phosphate transporter 
genes. A previous study has demonstrated that the transcript level of glucose-6-phosphate/phosphate translocator (GPT2) in Arabidopsis correlates with the sugar level in leaf [87], and another study has suggested that GPT2 functions as a plastid anti-porter transporting glucose-6-phosphate into the plastid to support starch biosynthesis [88]. Recently, a proteomic study has found that cucumber seed germination is enhanced by melatonin under high salt conditions via regulated energy metabolism and the up-regulation of proteins involved in glycolysis, the TCA cycle and the glyoxylate cycle [89]. The transcriptome results herein illustrated possible changes in the cellular respiratory pathway in transgenic rice under salt stress. These lines of evidence suggest that OsCam1-1 may confer salt tolerance by regulating central energy metabolism.

\section{Starch and sucrose metabolism}

Salt stress inhibited the activity of granule-bound starch synthase (GSSB) and suppressed the expression of GSSBI and GSSBII, resulting in a decrease in starch content in rice leaf [90]. An earlier report has shown that Pokkali, the standard salt-tolerant rice, shows significantly higher starch concentration under salt stress than KDML 105, which was identified as a salt-sensitive cultivar [91]. The transgenic KDML105 rice examined herein exhibited significant decrease in starch levels, but to a lesser extent than the wild type, while it showed improved maintenance of sucrose levels under salt stress, which probably reflected the higher salt tolerance ability. The transcriptome results revealed that several sucrose and starch degradation genes were up-regulated. An early report revealed that sucrose synthase, which its gene expression level was up-regulated to a higher level in transgenic rice, plays a role in starch synthesis by generating ADP-glucose or UDP-glucose through the cleavage of sucrose, which can be used for starch polymerization. Moreover, the findings showed that sucrose synthase activity correlated with starch and ADP-glucose accumulation in developing barley seed [92] and that transgenic potato plants with a disrupted sucrose synthase gene were defective in starch accumulation [93]. However, the transcriptome results herein showed that lower expression levels of several genes in the starch biosynthetic pathways in transgenic compared with wild type rice. These findings suggested that starch metabolism in higher plant might be regulated by several mechanisms: post-translational modifications such as redox modulation and protein phosphorylation, or allosteric modulation by metabolites, which is related to the metabolic flux [94]. Additionally, three invertase genes, encoding a sucrose-digesting enzyme, were identified as HT salt-responsive DEGs. A double mutant of two isoforms of Arabidopsis neutral invertase genes, inv1/ inv2, has been shown to exhibit severe growth defects, and therefore the authors suggested that cytosolic invertase may play role in supplying sucrose to Arabidopsis non-photosynthetic cells [95].

Together with the altered expression levels of these genes, our results for increased starch and sucrose levels in transgenic rice suggest that starch and sucrose metabolism are likely downstream components that are regulated by OsCam1-1 under salt stress. The down-regulation of photosynthetic genes due to the impact of OsCam1-1 and up-regulation of genes involved in lipid metabolism suggests that transgenic rice may balance carbon and energy metabolism under salt stress by obtaining monosaccharide units through the mobilization of lipids, which might be converted to sugar via the glyoxylate cycle and gluconeogenesis, as in previous discussions and/or the cell wall, which is a large carbon reservoir in the cell.

\section{OsCaM1 targets elucidating OsCaM1 downstream components}

Four known CaM-interacting proteins (CIPs) previously identified in other plants were obtained from the rice cDNA expression library screening indicating specific $\mathrm{CaM}$ target identification. Cyclic nucleotide-gated channels (CNGCs), one of the four known CIPs [30], are activated by binding cyclic nucleotide monophosphates, which play roles in ion-homeostasis control, development, and biotic or abiotic stress defense [96]. In Arabidopsis, AtCNGC10 functions in cation uptake in root, and AtCNGC10 antisense Arabidopsis lines are more salt-sensitive than wild type [97]. Another well-known CIP identified herein, glutamate decarboxylase (GAD), is the enzyme that converts L-glutamate to $\gamma$-amino butyric acid (GABA), which is involved in amino acid metabolism. CaM binds to GAD and regulates its activity, resulting in a balance of glutamate-GABA metabolism. Transgenic tobacco expressing petunia GAD lacking the CaM-binding domain exhibits a severely abnormal morphology associated with a high level of GABA but low level of glutamate [98].

Calmodulin-binding transcription activators (CAMTAs) are found in several species of multicellular organisms [32]. Herein, an OsCAMTA was confirmed to be a CaM target, even though the transcriptome showed that overexpression of OsCam1-1 and salt stress did not significantly affect the expression levels of its gene. In Arabidopsis, CAMTA3 regulates a set of biotic stress-responsive genes, and the camta3 Arabidopsis mutant showed enhanced biotic stress tolerance [99]. A rice kinesin motor domain-containing protein [33] was also confirmed as a CaM target in this study. Some evidence has revealed that kinesin motor 
domain-containing protein plays a role in cell developmental processes. In late anaphase, the amino-terminal motor kinesin (AtPAKRP1) is accumulated along the microtubule toward the spindle mid-zone and then localized to microtubules near the future cell plate area, suggesting that AtPAKRP1 may play a role in the maintenance or establishment of the phragmoplast microtubule array [100]. Another report has revealed that AtPAKRP2 first exhibits a punctate pattern in late anaphase, and then is concentrated at the division site following the appearance of the phragmoplast microtubule array in the mirror pair. Treatment with brefeldin A, which inhibits protein transportation from the endoplasmic reticulum to the Golgi apparatus, resulted in the alteration of AtPAKRP2 localization, so the authors suggested that AtPAKRP2 functions in Golgi-derived vesicles transportation in the phragmoplast [101].

Here, six CaM-interacting proteins that have not been found in other plant species were identified in rice. In Arabidopsis, hydroxycinnamoyl-coenzyme A shikimate/quinate hydroxycinnamoyltransferase (HCT) (AT5G48930), a homolog of LOC_Os02g39850, which was identified as CIP herein, contains acyltransferase activity capable of catalyzing the conversion $p$-coumaroyl-CoA to caffeoylCoA, which plays a role in the lignin biosynthesis pathway. Silencing of this acyltransferase gene in Arabidopsis results in a dwarf phenotype and change in lignin composition [102].

LOC_Os09g36220 was identified as OsPRR95, a pseudo response regulator, which takes part in circadian systems by binding a core oscillator to define rhythm to adapt to the daily changing environment [103]. OsPRR95 corresponds to Arabidopsis PRR, AtPRR5 or AtPRR9 [104]. A report has revealed that triple mutant prr9-11 prr7-10 prr5-10 Arabidopsis exhibit better salt, drought and cold tolerance than wild type, and thus suggested that PRR5, PRR7 and PRR9 are involved in the diurnal cold stress-initiating stress response by mediating the cyclic expression of stress response genes, including DREB1/CBF [105]. Additionally, Mesembryanthemum crystallinum (ice plant) CSP1, which is a class of pseudo-response regulator-like proteins, co-localizes with calcium-dependent protein kinase (McCDPK1) in the nucleus of $\mathrm{NaCl}$-stressed ice plants, suggesting that it may be regulated by McCDPK1 through reversible phosphorylation [106].

According to the MSU7 database, LOC_Os05g38710, the novel CaM1 target, is annotated as lipin, and the mRNA sequence of LOC_Os05g38710 is annotated as phosphatidate phosphatase (PAH1) [107]. A report has demonstrated that the $\mathrm{N}$ - and $\mathrm{C}$-terminal regions of mammalian lipin protein share sequence similarity to yeast PAH1 [108]. Phosphatidate phosphatase is the enzyme that converts phosphatidic acid to diacylglycerol and $\mathrm{P}_{i}$ [109]. In Phaseolus vulgaris cotyledons, phosphatidate phosphatase is stimulated by $\mathrm{Ca}^{2+}$ or $\mathrm{CaM}$ with $\mathrm{Ca}^{2+}$, and a possible role of $\mathrm{Ca}^{2+}$-second-messenger in membrane-lipid degradation initiation has been suggested [110]. Therefore, its identification as a CaM-interacting protein herein suggests that $\mathrm{Ca}^{2+} / \mathrm{CaM}$ stimulates phosphatidate phosphatase via direct binding.

By protein functional association analysis of each of these CIPs, the GO terms enriched in each set of resulting associated proteins that matched those from OsCam1-1 affected salt-responsive DEGs are presented in Fig. 10. Matched GO terms revealed interacting protein candidates that potentially regulate various cellular processes represented by each enriched GO term of the OsCam1-1 affected salt-responsive DEGs.

\section{Conclusion}

Transcriptome profiling revealed that $18.4 \%$ of salt-responsive DEGs are affected by OsCam1-1 overexpression, which has been previously found to confer salt stress tolerance to transgenic rice [17]. GSEA showed that the DEGs are mainly enriched in the terms of stress response and metabolic process, suggesting that overexpression of OsCam1-1 confers tolerance by regulating a wide range of processes, including signaling and stress response, hormone-mediated regulation, transcription, secondary metabolism, lipid metabolism, photosynthesis, carbohydrate and energy metabolism. The transcriptome data suggest that $\mathrm{CaM}$ action results in an enhancement of metabolic enzymes involved in central energy pathways, which may lead to the mobilization of carbon sources that benefits plant acclimation under salt stress during periods of decreased photosynthesis. The CaM1 target screening results consolidated knowledge that CaM1 downstream components are diverse, involving several cell systems and constituting a complex network of downstream components, as represented by the OsCam1-1 affected salt-responsive DEGs involved in $\mathrm{CaM}$-mediated salt stress response mechanisms in rice.

\section{Methods}

\section{Plant materials and stress treatment}

The rice Oryza sativa L. "Khao Dawk Mali 105" (KDML 105) and transgenic KDML 105 rice over-expressing OsCam1-1, generated in a previous work [17], were grown in a growth chamber (Humanlab, South Korea) with Yoshida's solution [111] for 1 week and then in the greenhouse for 2 weeks using a completely randomized design (CRD) with two biological replicates. Subsequently, the rice was treated with Yoshida's solution containing $150 \mathrm{mM} \mathrm{NaCl}$. The pooled tissues of leaf blade and leaf sheet were 


\begin{tabular}{|c|c|c|c|c|c|c|c|c|c|c|c|c|}
\hline \multirow[b]{3}{*}{ CaM1 interacting protein } & \multicolumn{4}{|c|}{$\begin{array}{l}\text { up-regulated salt responsive } \\
\text { Oscam1-1 effect DEGs }\end{array}$} & \multicolumn{8}{|c|}{ Down-regulated salt responsive Oscam 1-1 effect DEGs } \\
\hline & \multicolumn{3}{|c|}{$\mathrm{BP}$} & \multirow[b]{2}{*}{ 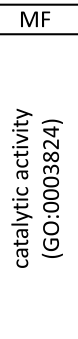 } & \multicolumn{3}{|c|}{$\mathrm{BP}$} & \multicolumn{2}{|c|}{$\mathrm{MF}$} & \multicolumn{3}{|c|}{$\mathrm{CC}$} \\
\hline & 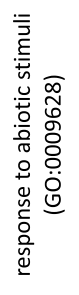 & 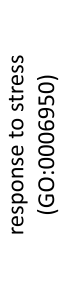 & 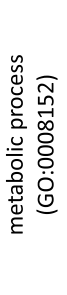 & & 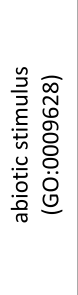 & 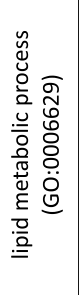 & 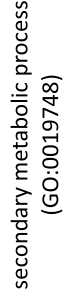 & 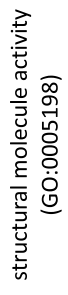 & 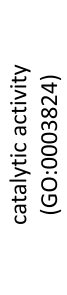 & 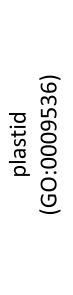 & 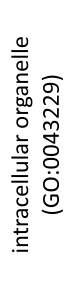 & 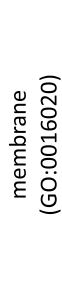 \\
\hline \multicolumn{13}{|l|}{ cyclic nucleotide-gated ion channel } \\
\hline \multicolumn{13}{|l|}{ glutamate decarboxylase } \\
\hline \multicolumn{13}{|l|}{ calmodulin-binding transcription activator } \\
\hline \multicolumn{13}{|l|}{ kinesin motor domain containing protein } \\
\hline \multicolumn{13}{|c|}{ hydroxyanthranilate hydroxycinnamoyl-transferase } \\
\hline \multicolumn{13}{|c|}{ response regulator receiver domain-containing protein } \\
\hline \multicolumn{13}{|c|}{ lipin, $\mathrm{N}$-terminal conserved region family protein } \\
\hline prefoldin & & & & & & & & & & & & \\
\hline
\end{tabular}

Fig. 10 The matched GO term of either up- or down-regulated OsCam1-1-effect genes obtaining from RNA-seq versus genes interacting with OsCaM1 targets from the STRING database

collected, rapidly frozen in liquid nitrogen and stored at $-80{ }^{\circ} \mathrm{C}$ for further analyses.

\section{RNA isolation}

The 3-week-old rice was treated with $150 \mathrm{mM} \mathrm{NaCl}$ for $4 \mathrm{~h}$, and then the leaves were collected and ground with liquid nitrogen using a chilled mortar and pestle. Subsequently, total RNA was isolated from the tissue using TRI Reagent ${ }^{\circ}$ (MRC, USA) following the manufacturer's instruction. After the RNA was precipitated and dissolved in DEPC-treated water, the concentration of RNA was determined using a spectrophotometer (Eppendorf, Germany) based on $\mathrm{A}_{260} / \mathrm{A}_{280}$, and the quality of the RNA was determined by agarose-gel electrophoresis.

\section{RNA-seq}

cDNA library preparation was initiated by isolating mRNA from the prepared total RNA using Dynabeads ${ }^{\circ}$ (Ambion $^{\mathrm{Tx}}$, USA), and then first-strand cDNA was synthesized from the mRNA template using Superscript III $^{\circ}$ reverse transcriptase (Invitrogen ${ }^{\mathrm{Tm}}$, USA). The mRNA template was eliminated by RNase $\mathrm{H}$ (Thermo Fisher Scientific, USA), and second-strand cDNA was synthesized using DNA polymerase I (Thermo Fisher Scientific, USA). The cDNA was fragmented, and the fragments were modified into blunt end fragments using End Repair Enzyme (New England Biolabs,
USA). Deoxyadenosines was added to the 3'end of the fragments by Klenow exo- (New England Biolabs, USA), and then the adapters were ligated to the end of the fragments that would later benefit the sample identification process, as each sample was ligated to a different adapter. The ligated fragments were amplified by PCR using Phusion ${ }^{\bullet}$ High-Fidelity DNA Polymerase (New England Biolabs, USA) with adapter primers, and the quality of the PCR products was checked by gel electrophoresis. Every step was followed by purification using AMPure (Beckman Coulter, USA). The cDNA libraries were subjected to single-read sequencing using an Illumina HiSeq 2000 (Illumina, USA).

\section{Data analysis}

The mRNA sequence data obtained from the genome analyzer were demultiplexed and mapped to MSU rice genome version 7 [23] using the computer command sets, Pipeline of Parentally Biased Expression (POPE) [22]. The gene expression data for the wild type and the transgenic rice under normal and salt stress condition were compared using DESeq [24]. Downstream data analyses, Venn diagram construction by the web-based software at http:// bioinformatics.psb.ugent.be/webtools/Venn/, and gene enrichment analysis by agriGO [112] were performed. Pathway analysis was conducted to illustrate genes in the pathway using MapMan software [113]. 


\section{Real-time RT-PCR}

Rice(s) growing, stress treatment and total RNA isolation were repeated with 4 biological replications. The isolated RNA was treated with DNaseI (Thermo Scientific $^{\text {TM }}$, USA) and converted to cDNA using the iScript ${ }^{\mathrm{TM}}$ cDNA synthesis kit (Bio-Rad, USA). Real-time RT-PCR was performed using SsoFast EvaGreen Supermix (Bio-Rad, USA) with the CFX96 ${ }^{\mathrm{Tm}}$ Real-Time PCR machine (Bio-Rad, USA) with EF-1- $\alpha$ as an internal control. The DNA primers used in this experiment were as follows: EF-1- $\alpha$ (LOC_Os03g08010) F-5'ATGGTTGTG GAGACCTTC3', R-5'TCACCTTGGCACCGGTTG3', aconitase (LOC_Os08g09200) F-5'CATCCTCCCATAC GTCATCC3', R-5'TGTCTCCTGCGGCTTTATTT3', isocitrate lyase (LOC_Os07g34520) F-5'AGAGCAGCA GCCATGTTCTT3', R-5'CGTGCGTGCTGTAGTTCA GT3', malate synthase (LOC_Os04g40990) F-5'CGTA CAACCTCATCGTGGTG3', R-5'CGGAGAAGTTACA CGGAGAGA3', AP2 (LOC_Os03g08470) F-5'CTGT GGAGCTTCGACGACTT3', R-5'ACAAACACAAAC ACCGCAAT3', ERD1 (LOC_Os02g32520) F-5'GAGC CACCTGAATGAGAAGG3', R-5' TTATATGCCCGAA CGAATCC3', glycosyl hydrolase (LOC_Os04g45290) F-5' GCTCAGGTGTGTGTGGTACA3', R-5'CGACAG CACACATCCTCTGT3', $\beta$-amylase (LOC_Os03g22790) F-5'ATGGATGATGCCCCCTGT3', R-5'TTGGGGTAC ACGTCTCATGT3', isocitrate dehydrogenase (LOC_Os05 g49760) F-5' TCGAGTCTGGGAAGATGACC3', R-5'AG TGCATCGGATCACATCAA3' and pyruvate decarboxylase (LOC_Os03g18220) F-5'AGGACGACACCAGCAAA GAG3', R-5' GAGGGAATGGACACAAGGAA3'.

\section{Sucrose and starch determination}

The 3-week-old rice grown in a CRD with five replicates was treated with $150 \mathrm{mM} \mathrm{NaCl}$ for 3 and 5 days, and then leaves were collected, lyophilized, ground and weighed. Sucrose extraction was performed according to Cowan A.K. et al. [114], and starch was extracted according to Alison and Samuel [115]. The samples for sucrose measurement were then treated with invertase (Sigma, USA) and those for starch measurement with $\alpha$ - and $\beta$-amylase (Sigma, USA), followed by incubation at $37^{\circ} \mathrm{C}$ for $2 \mathrm{~h}$. The amounts of sucrose and starch were determined based on glucose using the D-Fructose/D-Glucose test kit (Megazyme, Ireland). Potato starch (Sigma, USA) and sucrose (Sigma, USA) were used to construct standard curves.

\section{Gas exchange and fluorescence measurements}

The photosynthesis rate $\left(P_{n}\right)$, stomatal conductance $\left(g_{\mathrm{s}}\right)$, intercellular carbon dioxide $\left(C_{\mathrm{i}}\right)$, transpiration rate $(E)$ and $\mathrm{FV}^{\prime} / \mathrm{FM}^{\prime}$ of 3 -week-old transgenic and wild type rice, which were hydroponically grown under natural light in a CRD with five replicates, were measured using the LI-6400XT portable photosynthesis system (LI-COR ${ }^{\oplus}, \mathrm{USA}$ ) at day 3 and 5 of $150 \mathrm{mM} \mathrm{NaCl}$ treatment. The same parameters were also measured in untreated plants at each time point, and the data were compared.

\section{Statistical analysis}

Data from real-time RT-PCR, sucrose and starch determination, and gas exchange and fluorescence measurements were compared using analysis of variance (ANOVA), and then the means were compared with Duncan's multiple range test, with significance accepted at the $p<0.05$ level. Fisher's exact test was used to verify that genes in the known gene set were significantly over-presented in the list of OsCam1-1 affected DEGs or OsCaM1 targets, with significance accepted at the $\mathrm{p}<0.05$ level.

\section{Preparation of 35S-labeled rOsCaM1 protein}

The rOsCaM1 protein [116] was prepared according to Fromm and Chua [117] to be used as a probe for cDNA library expression screening. Production of the recombinant protein in $50 \mathrm{ml}$ cell culture of BL21(DE3) cells harboring pET-21a(+) containing a complete OsCam1-1 ORF was induced by IPTG. After 15 min of IPTG induction, $1 \mathrm{mCi}$ or Tran ${ }^{35} \mathrm{~S}$ Label $^{\mathrm{TM}}$ (MP Biomedicals, USA) was added to the culture, and the incubation was continued for $4 \mathrm{~h}$. After centrifugation, the pelleted cells were resuspended in $4 \mathrm{ml} \mathrm{B-PER}$ reagent containing $1 \mathrm{U} / \mathrm{ml}$ DNase I and $20 \mu \mathrm{g} / \mathrm{ml}$ lysozyme. The homogenate was heated in boiling water for $5 \mathrm{~min}$ and centrifuged at $15,000 \mathrm{xg}$ for $10 \mathrm{~min}$. The supernatant was collected, and the ${ }^{35} \mathrm{~S}$-labeled rOsCaM1 protein was purified by phenyl-sepharose chromatography in the presence of $\mathrm{Ca}^{2+}$ according to Liao and Zielinski [118].

\section{cDNA expression library construction}

The cDNA library was constructed by RNA isolation of $100 \mathrm{mM}$ NaCl-treated hydroponically grown 1-weekold KDML105 rice using TRI Reagent ${ }^{\circ}$ (MRC, USA) and mRNA purification using the Illustra ${ }^{\text {TM }}$ Quick Prep Micro mRNA Purification Kit (GE Healthcare, UK). cDNA synthesis and cDNA library construction were carried out using the Uni-ZAP XR vector system (Stratagene, USA). The cDNA was ligated to XhoI-EcoRI double-digested Uni-ZAP XR vector, and then the ligated mixture was packaged using Gigapack III packaging extract (Stratagene, USA). The packaging was performed using XL1-Blue MRF' $E$. coli cells, and the cells were cultured on NZY agar plates overlaid with NZY agar containing IPTG and X-gal for blue-white colony selection. The libraries were propagated in XL1-Blue MRF' E. coli, and the propagated libraries were stored in $0.3 \%(\mathrm{v} / \mathrm{v})$ chloroform at $4{ }^{\circ} \mathrm{C}$. 


\section{cDNA expression library screening}

Primary screening was carried out using the propagated library according to Chinpongpanich et al. [119]. The $600-\mu \mathrm{l}$ aliquots of XL1-Bule MRF2 cell suspension were mixed with the equivalent of $25,000 \mathrm{pfu}$ of the amplified library and incubated at $37^{\circ} \mathrm{C}$ for $15 \mathrm{~min}$ before plating as top agar with the addition of IPTG onto an LB agar plate. A prewetted nitrocellulose membrane was then placed onto each agar plate, followed by incubation at $37{ }^{\circ} \mathrm{C}$ overnight. The membranes were lifted, washed with $1 \mathrm{X}$ TBS buffer containing 0.05\% Tween-20 (TTBS), and incubated in Blocking Buffer (1X TBS buffer containing $0.05 \%(\mathrm{v} / \mathrm{v})$ Tween-20, $5 \mathrm{mM} \mathrm{CaCl}_{2}$ and $3 \%(w / v)$ skim milk). They were then washed twice in TTBS with $5 \mathrm{mM} \mathrm{CaCl}_{2}$ and incubated with ${ }^{35} \mathrm{~S}$-labeled rOsCaM1 probe solution for $1-4 \mathrm{~h}$. The membranes were washed twice in TTBS with $5 \mathrm{mM} \mathrm{CaCl}_{2}$ and air-dried overnight. Probe binding on the membranes was then detected by autoradiography, and positive plaques were selected for secondary and tertiary screening. The cDNA-containing pBluescript phagemid was excised from the Uni-ZAP XR vector using ExAssist helper phage with the E. coli SOLR strain, and the pBluescript phagemid was isolated and then sequenced using M13F and M13R universal primers.

\section{Protein blot analysis}

The E. coli strain SOLR cells harboring the cloned cDNA insert-containing pBluescript SK(-) plasmids were cultured and induced by IPTG addition at room temperature overnight. The OsCaM1-binding ability of the positive clones was examined using the ${ }^{35} \mathrm{~S}$-labeled rOsCaM1 probe. The duplicate blots were incubated in the probe solution and then separately washed in $1 \mathrm{X}$ TTBS containing $\mathrm{CaCl}_{2}$ or EDTA. Probe binding on the membrane was detected by autoradiography.

\section{Additional files}

Additional file 1: The DEG lists grouped by $H T$ salt-responsive DEG, LT salt-responsive DEG, HT DEG, LT DEG and salt-responsive DEG. This list contains locus number and annotation of the genes. (XLSX $2043 \mathrm{~kb}$ )

Additional file 2: The bar-chart showing expression level (RPKM) of photosynthetic DEGs in the rice(s) under both stress and normal condition. Bar-chart showing expression level of photosynthetic DEGs from RNA-seq data comparing between the transgenic rice overexpressing OsCam 1-1 under stress (150 mM NaCl) condition (L1S), wild type under stress (WTS), transgenic under non-stress (L1NS) and wild type under non-stress (WTNS), and the $Y$ axis represent RPKM. (PDF $171 \mathrm{~kb}$ )

Additional file 3: The bar-chart showing FV'/FM' of the rice(s) under either normal or salt-stress condition. Fluorescence measurement in leaf of the transgenic rice overexpressing OsCam 1-1 (L1, L2, L7) and wild type (WT) under normal and salt stress (150 $\mathrm{mM} \mathrm{NaCl}$ ) condition (A) at day 3 and (B) day 5 of treatment. (PDF $31 \mathrm{~kb}$ )

Additional file 4: The reliable testing of the 35S-labeled $\mathrm{rOsCaM1}$ binding for testing accuracy and specificity. Examination of the 35S-labeled rOsCaM1 protein, A) 12\% SDS-PAGE of the 35S-labeled rOsCaM1 elutes. Lane M:
Protein molecular weight marker. Lanes 1-4: Fractions 1-4 of the 35Slabeled rOsCaM1 elute, respectively, and B) Autoradiograph of the blot spotted with various amounts (as written above each spot) of positive (CaMKII peptide and calcineurin) or negative (BSA) control. (PDF 1805 kb)

Additional file 5: Autoradiographs of far western analysis of 11 putative OsCaM1-binding proteins. Lane M: protein molecular weight markers (negative control); Lane P: calcineurin (positive control); Lane N: crude protein extract from the SOLR cells harboring the pBluescript SK(-) plasmid (negative control); Numbers indicated above the lanes are clone No. assigned when these clones were isolated from the primary screening as following: 2, Cyclic nucleotide-gated ion channel (CNGC); 5, glutamate decarboxylase (GAD); 10, Hydroxyanthranilate hydroxyl cinnamoyltransferase (HHT); 12, CaM-binding transcription activator (CAMTA); 19, Kinesin motor domain- containing protein (KCBP); 21 , Kinesin motor domain- containing protein (KCBP); 23, Myosin heavy chain; 24, unknown expressed protein, while 18, 26 and 31 which represent response regulator receiver domain-containing protein (PRR), lipin, $\mathrm{N}$-terminal conserved region family protein, and another clone of Kinesin motor domain- containing protein (KCBP) respectively, were unclear. (PDF 8517 kb)

Additional file 6: The list of OsCam 1-1 co-expressed DEGs obtaining from STRING (Excel file). This list contains locus number and annotation of the genes. (XLSX $17 \mathrm{~kb}$ )

Additional file 7: The list of shared genes between OsCam1-1 coexpressed gene obtaining from STRING and DEGs affected by OsCam 1-1 overexpression from RNA-Seq result. This list contains locus number and annotation of the genes. (XLSX $12 \mathrm{~kb}$ )

Additional file 8: The list of rice homologous CaM target genes using known Arabidopsis CaM target gene as references. This list contains locus number and annotation of the genes. (XLSX $23 \mathrm{~kb}$ )

\section{Abbreviations}

CaM: Calmodulin; $C_{\mathrm{i}}$ : Intercellular carbon dioxide; CIP: CaM-interacting protein; CRD: Completely randomized design; DEG: Differentially expressed gene; $E$ : Transpiration rate; $g_{s}$ : Stomatal conductance; HT: DEGs whose expression levels were higher in the transgenic rice; KDML 105: Khao Dawk Mali 105; L1: Transgenic KDML 105 rice overexpressing OsCam 1-1 Line 1; L2: Transgenic KDML 105 rice overexpressing OsCam 1-1 Line 2;

L7: Transgenic KDML 105 rice overexpressing OsCam 1-1 Line 7; LT: DEGs whose expression levels were lower in the transgenic rice; NS: Non-stress / normal condition; $P_{n}$ : Photosynthesis Rate; POPE: Pipeline of Parentally Biased Expression; RPKM: Read Per Kilobase of Transcript Per Million Mapped Reads; S : Stress condition; TF: Transcription Factor; WT: Wild Type; WTNS: WT under non-stress; WTS: WT under stress

\section{Acknowledgments}

We would like to sincerely thank Ms. Thammaporn Kojonna and Mr. Chakkree Lekklar for kind assistance with the gas exchange and fluorescence measurement experiments, and Ms. Srivilai Phean-o-pas with the cDNA expression screening experiments.

\section{Funding}

This work was supported by Thailand Research Fund (No. BRG5680019) to T.B. W.Y. was supported by the Royal Golden Jubilee Ph.D. Program-RGJ (PHD/0043/2556-4.C.CU/56/G.1.O.XX) from the Thailand Research Fund.

\section{Availability of data and materials}

The datasets used and/or analysed during the current study are available from the corresponding author on reasonable request.

\section{Authors' contributions}

WY and AC carried out the laboratory work in collaboration with LC and SC, $W Y$ and TB performed the data analysis and interpretation. WY prepared the figures and tables. WY and TB drafted the manuscript with commentary from LC and SC. All authors read and approved the final manuscript.

Ethics approval and consent to participate Not applicable. 


\section{Consent for publication}

Not applicable.

\section{Competing interests}

The authors declare that they have no competing interests.

\section{Publisher's Note}

Springer Nature remains neutral with regard to jurisdictional claims in published maps and institutional affiliations.

\section{Author details}

'Department of Biochemistry, Faculty of Science, Chulalongkorn University, Bangkok, Thailand. 'Department of Plant Biology and Genome Center, University of California Davis, Davis, CA 795616, USA. ${ }^{3}$ Center of Excellent in Environment and Plant Physiology, Department of Botany, Faculty of Science, Chulalongkorn University, Bangkok, Thailand. ${ }^{4}$ Omics Sciences and Bioinformatics Center, Faculty of Science, Chulalongkorn University, Bangkok, Thailand.

\section{Received: 20 September 2018 Accepted: 20 November 2018} Published online: 05 December 2018

\section{References}

1. Munns R, Tester M. Mechanisms of salinity tolerance. Annu Rev Plant Biol. 2008;59(1):651-81.

2. Horie T, Karahara I, Katsuhara M. Salinity tolerance mechanisms in glycophytes: an overview with the central focus on rice plants. Rice. 2012;5(1):11.

3. Läuchli A, Grattan SR. Plant growth and development under salinity stress. In: Jenks MA, Hasegawa PM, Jain SM, editors. Advances in molecular breeding toward drought and salt tolerant crops. Dordrecht: Springer Netherlands; 2007. p. 1-32.

4. Lutts S, Kinet JM, Bouharmont J. NaCl-induced senescence in leaves of Rice ( Oryza sativa L.) cultivars differing in salinity resistance. Ann Bot. 1996;78(3):389-98

5. Moradi F, Ismail AM. Responses of photosynthesis, chlorophyll fluorescence and ROS-Scavenging Systems to salt stress during seedling and reproductive stages in Rice. Ann Bot. 2007:99(6):1161-73.

6. Zeng L, Shannon MC, Lesch SM. Timing of salinity stress affects rice growth and yield components. Agric Water Manag. 2001:48(3):191-206.

7. Kudla J, Batistič O, Hashimoto K. Calcium signals: the Lead currency of plant information processing. Plant Cell. 2010;22(3):541-63.

8. Knight H. Calcium signaling during abiotic stress in plants. In: International Review of Cytology - a Survey of Cell Biology. Vol. 195; 2000. p. 269-324.

9. Yang T, Poovaiah BW. Calcium/calmodulin-mediated signal network in plants. Trends Plant Sci. 2003;8(10):505-12

10. Means AR, Dedman JR. Calmodulin an intracellular calcium receptor. Nature. 1980;285(5760):73-7

11. Day IS, Reddy VS, Shad Ali G, Reddy ASN. Analysis of EF-hand-containing proteins in Arabidopsis. Genome Biol. 2002;3(10):RESEARCH0056.

12. Boonburapong B, Buaboocha T. Genome-wide identification and analyses of the rice calmodulin and related potential calcium sensor proteins. BMC Plant Biol. 2007;7(1):4.

13. Phean-o-Pas S, Punteeranurak P, Buaboocha T. Calcium signaling-mediated and differential induction of calmodulin gene expression by stress in Oryza sativa L. J Biochem Mol Biol. 2005:38(4):432-9.

14. Botella JR, Arteca RN. Differential expression of two calmodulin genes in response to physical and chemical stimuli. Plant Mol Biol. 1994;24(5):757-66.

15. Olsson P, Yilmaz JL, Sommarin M, Persson S, Bülow L. Expression of bovine calmodulin in tobacco plants confers faster germination on saline media. Plant Sci. 2004;166(6):1595-604

16. Yoo JH, Park CY, Kim JC, Do Heo W, Cheong MS, Park HC, Kim MC, Moon BC, Choi MS, Kang YH, et al. Direct interaction of a divergent CaM isoform and the transcription factor, MYB2, enhances salt tolerance in Arabidopsis. J Biol Chem. 2005;280(5):3697-706.

17. Saeng-ngam S, Takpirom W, Buaboocha T, Chadchawan S. The role of the OsCam1-1 salt stress sensor in ABA accumulation and salt tolerance in rice. J Plant Biol. 2012;55(3):198-208

18. Wu HC, Luo DL, Vignols F, Jinn TL. Heat shock-induced biphasic Ca2+ signature and OsCaM1-1 nuclear localization mediate downstream signaling in acquisition of thermotolerance in rice (Oryza sativa L.). Plant Cell Environ. 2012;35(9):1543-57.
19. Zhang W, Zhou R-G, Gao Y-J, Zheng S-Z, Xu P, Zhang S-Q, Sun D-Y. Molecular and genetic evidence for the key role of AtCaM3 in heat-shock signal transduction in Arabidopsis. Plant Physiol. 2009;149(4):1773-84.

20. Choi MS, Kim MC, Yoo JH, Moon BC, Koo SC, Park BO, Lee JH, Koo YD, Han $\mathrm{HJ}$, Lee $\mathrm{SY}$, et al. Isolation of a calmodulin-binding transcription Factor from Rice (Oryza sativa L.). J Biol Chem. 2005;280(49):40820-31.

21. Reddy ASN, Ali GS, Celesnik H, Day IS. Coping with stresses: roles of calcium- and calcium/calmodulin-regulated gene expression. Plant Cell. 2011;23(6):2010-32.

22. Missirian V, Henry I, Comai L, Filkov V. POPE: pipeline of parentally-biased expression. In: Bleris L, Măndoiu I, Schwartz R, Berlin WJ, editors. Bioinformatics research and applications: 8th international symposium, ISBRA 2012, Dallas, TX, USA, may 21-23, 2012 proceedings. Heidelberg: Springer Berlin Heidelberg; 2012. p. 177-88

23. Kawahara $Y$, de la Bastide M, Hamilton JP, Kanamori H, McCombie WR, Ouyang S, Schwartz DC, Tanaka T, Wu J, Zhou S, et al. Improvement of the Oryza sativa Nipponbare reference genome using next generation sequence and optical map data. Rice. 2013;6(1):1-10.

24. Anders $\mathrm{S}$, Huber W. Differential expression analysis for sequence count data. Genome Biol. 2010;11(10):R106

25. Chinpongpanich A, Limruengroj K, Phean-o-pas S, Limpaseni T, Buaboocha T. Expression analysis of calmodulin and calmodulin-like genes from rice, Oryza sativa L. BMC Res Notes. 2012;5(1):625.

26. Baker NR. Chlorophyll fluorescence: a probe of photosynthesis in vivo. Annu Rev Plant Biol. 2008;59(1):89-113.

27. Basavappa S, Mangel AW, Scott L, Liddle RA. Activation of calcium channels by CAMP in STC-1 cells is dependent upon Ca2+calmodulin-dependent protein kinase II. Biochem Biophys Res Commun. 1999:254(3):699-702.

28. Klee CB, Crouch TH, Krinks MH. Calcineurin: a calcium- and calmodulinbinding protein of the nervous system. Proc Natl Acad Sci. 1979:76(12):6270.

29. Ohyanagi H, Tanaka T, Sakai H, Shigemoto Y, Yamaguchi K, Habara T, Fujii $Y$, Antonio BA, Nagamura Y, Imanishi T, et al. The Rice annotation project database (RAP-DB): hub for Oryza sativa ssp. japonica genome information. Nucleic Acids Res. 2006:34(suppl_1):D741-4.

30. Schuurink RC, Shartzer SF, Fath A, Jones RL. Characterization of a calmodulin-binding transporter from the plasma membrane of barley aleurone. Proc Natl Acad Sci. 1998;95(4):1944-9.

31. Baum G, Chen Y, Arazi T, Takatsuji H, Fromm H. A plant glutamate decarboxylase containing a calmodulin binding domain. Cloning, sequence, and functional analysis. J Biol Chem. 1993;268(26):19610-7.

32. Bouché $N$, Scharlat A, Snedden W, Bouchez D, Fromm H. A novel family of calmodulin-binding transcription activators in multicellular organisms. J Biol Chem. 2002;277(24):21851-61.

33. Reddy ASN, Safadi F, Narasimhulu SB, Golovkin M, Hu X. A novel plant calmodulin-binding protein with a kinesin heavy chain motor domain. J Biol Chem. 1996;271(12):7052-60.

34. Szklarczyk D, Morris JH, Cook H, Kuhn M, Wyder S, Simonovic M, Santos A Doncheva NT, Roth A, Bork P, et al. The STRING database in 2017: qualitycontrolled protein-protein association networks, made broadly accessible. Nucleic Acids Res. 2017:45(D1):D362-8.

35. Reddy VS, Ali GS, Reddy ASN. Genes encoding calmodulin-binding proteins in the Arabidopsis genome. J Biol Chem. 2002;277(12):9840-52.

36. Fujita M, Fujita Y, Noutoshi Y, Takahashi F, Narusaka Y, Yamaguchi-Shinozaki K, Shinozaki K. Crosstalk between abiotic and biotic stress responses: a current view from the points of convergence in the stress signaling networks. Curr Opin Plant Biol. 2006;9(4):436-42.

37. Katou S, Kuroda K, Seo S, Yanagawa Y, Tsuge T, Yamazaki M, Miyao A, Hirochika H, Ohashi Y. A calmodulin-binding mitogen-activated protein kinase phosphatase is induced by wounding and regulates the activities of stress-related mitogen-activated protein kinases in Rice. Plant Cell Physiol. 2007:48(2):332-44.

38. Takahashi F, Mizoguchi T, Yoshida R, Ichimura K, Shinozaki K. Calmodulindependent activation of MAP kinase for ROS homeostasis in Arabidopsis. Mol Cell. 2011:41(6):649-60.

39. Cheong YH, Moon BC, Kim JK, Kim CY, Kim MC, Kim IH, Park CY, Kim JC, Park BO, Koo SC, et al. BWMK1, a Rice mitogen-activated protein kinase, locates in the nucleus and mediates pathogenesis-related gene expression by activation of a transcription factor. Plant Physiol. 2003;132(4):1961-72.

40. Tang $Y$, Tan S, Xue H. Arabidopsis inositol 1,3,4-trisphosphate 5/6 kinase 2 is required for seed coat development. Acta Biochim Biophys Sin. 2013;45(7):549-60 
41. Du H, Liu L, You L, Yang M, He Y, Li X, Xiong L. Characterization of an inositol 1,3,4-trisphosphate 5/6-kinase gene that is essential for drought and salt stress responses in rice. Plant Mol Biol. 2011;77(6):547-63.

42. Arisz SA, Testerink C, Munnik T. Plant PA signaling via diacylglycerol kinase. Biochim Biophys Acta. 2009;1791(9):869-75.

43. Canonne J, Froidure-Nicolas S, Rivas S. Phospholipases in action during plant defense signaling. Plant Signal Behav. 2011;6(1):13-8.

44. Weidong Z, Jie C, Huijuan Z, Fengming S. Overexpression of a Rice diacylglycerol kinase gene OsBIDK1 enhances disease resistance in transgenic tobacco. Mol Cells. 2008;26(3):258-64.

45. Loukehaich R, Wang T, Ouyang B, Ziaf K, Li H, Zhang J, Lu Y, Ye Z. SpUSP, an annexin-interacting universal stress protein, enhances drought tolerance in tomato. J Exp Bot. 2012;63(15):5593-606.

46. Tokunaga T, Esaka M. Induction of a novel XIP-type xylanase inhibitor by external ascorbic acid treatment and differential expression of XIP-family genes in Rice. Plant Cell Physiol. 2007;48(5):700-14.

47. Peleg Z, Blumwald E. Hormone balance and abiotic stress tolerance in crop plants. Curr Opin Plant Biol. 2011;14(3):290-5.

48. Sah SK, Reddy KR, Li J. Abscisic acid and abiotic stress tolerance in crop plants. Front Plant Sci. 2016;7:571.

49. Feussner I, Wasternack C. The lipoxygenase pathway. Annu Rev Plant Biol. 2002;53(1):275-97.

50. Ahmad P, Rasool S, Gul A, Sheikh SA, Akram NA, Ashraf M, Kazi AM, Gucel S. Jasmonates: multifunctional roles in stress tolerance. Front Plant Sci. 2016;7:813.

51. Kazan K. Diverse roles of jasmonates and ethylene in abiotic stress tolerance. Trends Plant Sci. 2015;20(4):219-29.

52. Bell E, Creelman RA, Mullet JE. A chloroplast lipoxygenase is required for wound-induced jasmonic acid accumulation in Arabidopsis. Proc Natl Acad Sci U S A. 1995;92(19):8675-9.

53. Sobajima H, Takeda M, Sugimori M, Kobashi N, Kiribuchi K, Cho E-M, Akimoto C, Yamaguchi T, Minami E, Shibuya N, et al. Cloning and characterization of a jasmonic acid-responsive gene encoding 12-oxophytodienoic acid reductase in suspension-cultured rice cells. Planta. 2003;216(4):692-8.

54. Eiji N, Annie M-P. Abscisic acid biosynthesis and catabolism. Annu Rev Plant Biol. 2005;56(1):165-85

55. Xiong L, Zhu J-K. Regulation of abscisic acid biosynthesis. Plant Physiol. 2003;133(1):29-36

56. CristinaRodriguez $M$, Petersen $M$, Mundy J. Mitogen-activated protein kinase signaling in plants. Annu Rev Plant Biol. 2010;61(1):621-49.

57. Nakashima K, Ito Y, Yamaguchi-Shinozaki K. Transcriptional regulatory networks in response to abiotic stresses in Arabidopsis and grasses. Plant Physiol. 2009;149(1):88-95.

58. Singh KB, Foley RC, Oñate-Sánchez $L$. Transcription factors in plant defense and stress responses. Curr Opin Plant Biol. 2002;5(5):430-6.

59. Guo Y, Huang R, Duan L, Wang J. The APETALA2/ethylene-responsive factor transcription factor OsDERF2 negatively modulates drought stress in rice by repressing abscisic acid responsive genes. J Agric Sci. 2017;155(6):966-77.

60. Licausi F, Ohme-Takagi M, Perata P. APETALA2/ethylene responsive factor (AP2/ERF) transcription factors: mediators of stress responses and developmental programs. New Phytol. 2013;199(3):639-49.

61. Nakano T, Suzuki K, Fujimura T, Shinshi H. Genome-wide analysis of the ERF gene family in Arabidopsis and Rice. Plant Physiol. 2006;140(2):411-32.

62. Dubouzet JG, Sakuma Y, Ito Y, Kasuga M, Dubouzet EG, Miura S, Seki M, Shinozaki K, Yamaguchi-Shinozaki K. OsDREB genes in rice, Oryza sativa L., encode transcription activators that function in drought-, high-salt- and cold-responsive gene expression. Plant J. 2003;33(4):751-63.

63. Yanhui $C$, Xiaoyuan $Y$, Kun $H$, Meihua $L$, Jigang $L$, Zhaofeng $G$, Zhiqiang $L$, Yunfei Z, Xiaoxiao W, Xiaoming Q, et al. The MYB transcription factor superfamily of Arabidopsis: expression analysis and phylogenetic comparison with the Rice MYB family. Plant Mol Biol. 2006:60(1):107-24.

64. Xiong H, Li J, Liu P, Duan J, Zhao Y, Guo X, Li Y, Zhang H, Ali J, Li Z. Overexpression of OsMYB48-1, a novel MYB-related transcription factor, enhances drought and salinity tolerance in Rice. PLoS One. 2014;9(3):e92913.

65. Jiang J, Ma S, Ye N, Jiang M, Cao J, Zhang J. WRKY transcription factors in plant responses to stresses. J Integr Plant Biol. 2017;59(2):86-101.

66. Hu L, Ye M, Li R, Zhang T, Zhou G, Wang Q, Lu J, Lou Y. The Rice transcription factor WRKY53 suppresses herbivore-induced defenses by acting as a negative feedback modulator of mitogen-activated protein kinase activity. Plant Physiol. 2015;169(4):2907-21.
67. Liu $X$, Bai $X$, Wang $X$, Chu C. OsWRKY71, a rice transcription factor, is involved in rice defense response. J Plant Physiol. 2007;164(8):969-79.

68. Xiao J, Cheng H, Li X, Xiao J, Xu C, Wang S. Rice WRKY13 regulates cross talk between abiotic and biotic stress signaling pathways by selective binding to different cis-elements. Plant Physiol. 2013;163(4):1868-82.

69. Liu J, Chen X, Liang X, Zhou X, Yang F, Liu J, He SY, Guo Z. Alternative splicing of Rice WRKY62 and WRKY76 transcription factor genes in pathogen defense. Plant Physiol. 2016;171(2):1427-42.

70. Akula R, Ravishankar GA. Influence of abiotic stress signals on secondary metabolites in plants. Plant Signal Behav. 2011;6(11):1720-31.

71. Ajjawi I, Shintani D. Engineered plants with elevated vitamin E: a nutraceutical success story. Trends Biotechnol. 2004;22(3):104-7.

72. Falk Jon KN, Dähnhardt D, Krupinska K. The senescence associated gene of barley encoding 4-hydroxyphenylpyruvate dioxygenase is expressed during oxidative stress. J Plant Physiol. 2002;159(11):1245-53.

73. Huang MT, Lu YC, Zhang S, Luo F, Yang H. Rice (Oryza sativa) laccases involved in modification and detoxification of herbicides atrazine and Isoproturon residues in plants. J Agric Food Chem. 2016;64(33):6397-406.

74. Cai X, Davis EJ, Ballif J, Liang M, Bushman E, Haroldsen V, Torabinejad J, Wu Y. Mutant identification and characterization of the laccase gene family in Arabidopsis. J Exp Bot. 2006;57(11):2563-9.

75. Todd J, Post-Beittenmiller D, Jaworski Jan G. KCS1encodes a fatty acid elongase 3-ketoacyl-CoA synthase affecting wax biosynthesis inArabidopsis thaliana. Plant J. 1999;17(2):119-30.

76. Lee S-B, Jung S-J, Go Y-S, Kim H-U, Kim J-K, Cho H-J, Park OK, Suh M-C. Two Arabidopsis 3-ketoacyl CoA synthase genes, KCS20 and KCS2/DAISY, are functionally redundant in cuticular wax and root suberin biosynthesis, but differentially controlled by osmotic stress. Plant J. 2009;60(3):462-75.

77. Li W, Ling H, Zhang F, Yao H, Sun X, Tang K. Analysis of Arabidopsis genes encoding putative class III lipases. J Plant Biochem Biotechnol. 2012;21(2):261-7.

78. Dieuaide M, Couée I, Pradet A, Raymond P. Effects of glucose starvation on the oxidation of fatty acids by maize root tip mitochondria and peroxisomes: evidence for mitochondrial fatty acid $\beta$-oxidation and acylCoA dehydrogenase activity in a higher plant. Biochem J. 1993;296(1):199.

79. Fernie AR, Carrari F, Sweetlove LJ. Respiratory metabolism: glycolysis, the TCA cycle and mitochondrial electron transport. Curr Opin Plant Biol. 2004;7(3):254-61.

80. Lee D-G, Woong Park K, Young An J, Geol Sohn Y, Ki Ha J, Yoon Kim H, Won Bae D, Hee Lee $\mathrm{K}$, Jun Kang N, Lee B-H, et al. Proteomics analysis of salt-induced leaf proteins in two rice germplasms with different salt sensitivity. Can J Plant Sci. 2011;91(2):337-49.

81. Rasoulnia A, Bihamta MR, Peyghambari SA, Alizadeh H, Rahnama A. Proteomic response of barley leaves to salinity. Mol Biol Rep. 2011;38(8):5055-63.

82. Suzuki M, Hashioka A, Mimura T, Ashihara H. Salt stress and glycolytic regulation in suspension-cultured cells of the mangrove tree, Bruguiera sexangula. Physiol Plant. 2005;123(3):246-53.

83. Moeder W, del Pozo O, Navarre DA, Martin GB, Klessig DF. Aconitase plays a role in regulating resistance to oxidative stress and cell death in Arabidopsis and Nicotiana benthamiana. Plant Mol Biol. 2007;63(2):273-87.

84. Liu Y, Shi Y, Song Y, Wang T, Li Y. Characterization of a stress-induced NADP-isocitrate dehydrogenase gene in maize confers salt tolerance in Arabidopsis. J Plant Biol. 2010:53(2):107-12.

85. Cornah JE, Germain V, Ward JL, Beale MH, Smith SM. Lipid utilization, gluconeogenesis, and seedling growth in Arabidopsis mutants lacking the Glyoxylate cycle enzyme malate synthase. J Biol Chem. 2004;279(41):42916-23.

86. Eastmond PJ, Germain V, Lange PR, Bryce JH, Smith SM, Graham IA. Postgerminative growth and lipid catabolism in oilseeds lacking the gloxylate cycle. Proc Natl Acad Sci U S A. 2000;97(10):5669-74.

87. Kunz HH, Häusler RE, Fettke J, Herbst K, Niewiadomski P, Gierth M, Bell K, Steup M, Flügge UI, Schneider A. The role of plastidial glucose-6-phosphate/ phosphate translocators in vegetative tissues of Arabidopsis thaliana mutants impaired in starch biosynthesis. Plant Biol. 2010;12:115-28.

88. Kammerer B, Fischer K, Hilpert B, Schubert S, Gutensohn M, Weber A, Flügge U-I. Molecular characterization of a carbon transporter in plastids from heterotrophic tissues: the glucose 6-phosphate/phosphate antiporter. Plant Cell. 1998;10(1):105-17.

89. Zhang N, Zhang H-J, Sun Q-Q, Cao Y-Y, Li X, Zhao B, Wu P, Guo Y-D. Proteomic analysis reveals a role of melatonin in promoting cucumber seed germination under high salinity by regulating energy production. Sci Rep. 2017;7(1):503. 
90. Chen H-J, Chen J-Y, Wang S-J. Molecular regulation of starch accumulation in rice seedling leaves in response to salt stress. Acta Physiol Plant. 2008; 30(2):135-42.

91. Pattanagul W, Thitisaksakul M. Effect of salinity stress on growth and carbohydrate metabolism in three Rice (Oryza sativa L.) cultivars differing in salinity tolerance. Indian J Exp Biol. 2008:46(10):736-42.

92. Baroja-Fernández E, Muñoz FJ, Saikusa T, Rodríguez-López M, Akazawa T, Pozueta-Romero J. Sucrose synthase catalyzes the de novo production of ADPglucose linked to starch biosynthesis in heterotrophic tissues of plants. Plant Cell Physiol. 2003;44(5):500-9.

93. Zrenner R, Salanoubat M, Willmitzer L, Sonnewald U. Evidence of the crucial role of sucrose synthase for sink strength using transgenic potato plants (Solanum tuberosum L.). Plant J. 1995;7(1):97-107.

94. Tetlow IJ, Morell MK, Emes M. Recent developments in understanding the regulation of starch metabolism in higher plants. J Exp Bot. 2004;55(406):2131-45.

95. Barratt DHP, Derbyshire P, Findlay K, Pike M, Wellner N, Lunn J, Feil R, Simpson C, Maule AJ, Smith AM. Normal growth of Arabidopsis requires cytosolic invertase but not sucrose synthase. Proc Natl Acad Sci. 2009; 106(31):13124-9.

96. Kaplan B, Sherman T, Fromm H. Cyclic nucleotide-gated channels in plants. FEBS Lett. 2007:581(12):2237-46.

97. Kun-Mei G, Olga B, CD A, Tamas B, Zed R. The cyclic nucleotide-gated channel, AtCNGC10, influences salt tolerance in Arabidopsis. Physiol Plant. 2008;134(3):499-507.

98. Baum G, Lev-Yadun S, Fridmann Y, Arazi T, Katsnelson H, Zik M, Fromm H. Calmodulin binding to glutamate decarboxylase is required for regulation of glutamate and GABA metabolism and normal development in plants. EMBO J. 1996;15(12):2988-96.

99. Galon Y, Nave R, Boyce JM, Nachmias D, Knight MR, Fromm H. Calmodulinbinding transcription activator (CAMTA) 3 mediates biotic defense responses in Arabidopsis. FEBS Lett. 2008;582(6):943-8.

100. Lee YRJ, Liu B. Identification of a phragmoplast-associated kinesin-related protein in higher plants. Curr Biol. 2000;10(13):797-800

101. Lee Y-RJ, Giang HM, Liu B. A novel plant kinesin-related protein specifically associates with the Phragmoplast organelles. Plant Cell. 2001;13(11):2427-39.

102. Hoffmann L, Besseau S, Geoffroy P, Ritzenthaler C, Meyer D, Lapierre C Pollet B, Legrand M. Silencing of Hydroxycinnamoyl-coenzyme a shikimate/ Quinate Hydroxycinnamoyltransferase affects Phenylpropanoid biosynthesis. Plant Cell. 2004;16(6):1446-65.

103. Campoli C, Shtaya M, Davis SJ, von Korff M. Expression conservation within the circadian clock of a monocot: natural variation at barley Ppd-H1affects circadian expression of flowering time genes, but not clock orthologs. BMC Plant Biol. 2012;12(1):97.

104. Murakami M, Ashikari M, Miura K, Yamashino T, Mizuno T. The evolutionarily conserved OsPRR quintet: Rice Pseudo-response regulators implicated in circadian rhythm. Plant Cell Physiol. 2003;44(11):1229-36.

105. Nakamichi N, Kusano M, Fukushima A, Kita M, Ito S, Yamashino T, Saito K, Sakakibara H, Mizuno T. Transcript profiling of an Arabidopsis PSEUDO RESPONSE REGULATOR arrhythmic triple mutant reveals a role for the circadian clock in cold stress response. Plant Cell Physiol. 2009;50(3):447-62.

106. Rahul PO, CJ C. A stress-induced calcium-dependent protein kinase from Mesembryanthemum crystallinum phosphorylates a two-component pseudo-response regulator. Plant J. 2000;24(5):679-91.

107. Kikuchi S, Satoh K, Nagata T, Kawagashira N, Doi K, Kishimoto N, Yazaki J, Ishikawa M, Yamada H, Ooka H, et al. Collection, mapping, and annotation of over 28,000 cDNA clones from japonica Rice. Science. 2003;301(5631):376-9.

108. Péterfy M, Phan J, Xu P, Reue K. Lipodystrophy in the fld mouse results from mutation of a new gene encoding a nuclear protein, lipin. Nat Genet. 2001;27:121

109. Smith SW, Weiss SB, Kennedy EP. The enzymatic Dephosphorylation of phosphatidic acids. J Biol Chem. 1957;228(2):915-22.

110. Paliyath G, Thompson JE. Calcium- and calmodulin-regulated breakdown of phospholipid by microsomal membranes from bean cotyledons. Plant Physiol. 1987:83(1):63-8.

111. Yoshida S, Forno DA, Cock JH. Laboratory manual for physiologica studies of rice; 1971.

112. Du Z, Zhou X, Ling Y, Zhang Z, Su Z. agriGO: a GO analysis toolkit for the agricultural community. Nucleic Acids Res. 2010;38(suppl 2):W64-70
113. Usadel B, Poree F, Nagel A, Lohse M, Czedik-Eysenberg A, Stitt M. A guide to using MapMan to visualize and compare omics data in plants: a case study in the crop species, maize. Plant Cell Environ. 2009;32(9):1211-29.

114. Cowan AK, Freeman M, Björkman P-O, Nicander B, Sitbon F, Tillberg E. Effects of senescence-induced alteration in cytokinin metabolism on sourcesink relationships and ontogenic and stress-induced transitions in tobacco. Planta. 2005;221(6):801-14.

115. Smith AM, Zeeman SC. Quantification of starch in plant tissues. Nat Protocols. 2006;1(3):1342-5.

116. Phean-o-pas S, Limpaseni T, Buaboocha T. Structure and expression analysis of the OsCam1-1 calmodulin gene from Oryza sativa L. BMB Rep. 2008; 41(11):771-7.

117. Fromm H, Chua N-H. Cloning of plant CDNAs encoding calmodulin-binding proteins using35S-labeled recombinant calmodulin as a probe. Plant Mol Biol Report. 1992:10(2):199-206.

118. Liao B, Zielinski RE: Production of recombinant plant calmodulin and its use to detect calmodulin-binding proteins. In: Galbraith DW, Bohnert HJ, Bourque DP, editors. Methods in Cell Biology. Massachusetts: Academic Press; 1995. p. 487-500.

119. Chinpongpanich A, Phean-O-Pas S, Thongchuang M, Qu L-J, Buaboocha T. C-terminal extension of calmodulin-like 3 protein from Oryza sativa L.: interaction with a high mobility group target protein. Acta Biochim Biophys Sin. 2015;47(11):880-9.
Ready to submit your research? Choose BMC and benefit from:

- fast, convenient online submission

- thorough peer review by experienced researchers in your field

- rapid publication on acceptance

- support for research data, including large and complex data types

- gold Open Access which fosters wider collaboration and increased citations

- maximum visibility for your research: over $100 \mathrm{M}$ website views per year

At BMC, research is always in progress.

Learn more biomedcentral.com/submissions 